\title{
Validation of Himawari-8/AHI Radiometric Calibration Based on Two Years of In-Orbit Data
}

\author{
Arata OKUYAMA, Masaya TAKAHASHI, Kenji DATE, \\ Keita HOSAKA, Hidehiko MURATA, Tasuku TABATA \\ Meteorological Satellite Center, Japan Meteorological Agency, Tokyo, Japan \\ and \\ Ryoko YOSHINO \\ Institute of Space and Astronautical Science, Japan Aerospace Exploration Agency, Kanagawa, Japan
}

(Manuscript received 6 June 2017, in final form 30 October 2017)

\begin{abstract}
The new geostationary (GEO) meteorological satellite of the Japan Meteorological Agency (JMA), Himawari-8, entered operation on 7 July 2015. Himawari-8 features the new 16-band Advanced Himawari Imager (AHI), whose spatial resolution and observation frequency are improved over those of its predecessor MTSAT-series satellites. These improvements will bring about unprecedented levels of performance in nowcasting services and short-range weather forecasting systems. In view of the essential nature of navigation and radiometric calibration in fully leveraging the imager's potential, this study reports on the current status of calibration for the AHI. Image navigation is accurate to within $1 \mathrm{~km}$, and band-to-band coregistration has also been validated. Infrared (IR) band calibration is accurate to within $0.2 \mathrm{~K}$ with no significant diurnal variation and is being validated using an approach developed under the Global Space-based Inter-Calibration System (GSICS) framework. Validation approaches are currently being tested for the visible and near-IR (NIR) bands. Two such approaches were compared and found to produce largely consistent results.
\end{abstract}

Keywords Himawari-8; Advanced Himawari Imager; geostationary satellite; satellite data calibration; intercalibration

\section{Introduction}

The new-generation geostationary (GEO) meteorological satellite of the Japan Meteorological Agency (JMA), Himawari-8, was successfully launched on 7 October 2014. The satellite started operation on 7 July 2015 after the completion of overall-system checking. Himawari-8 features the new Advanced Himawari

Corresponding author and present affiliation: Arata Okuyama, Japan Meteorological Agency, 1-3-4, Ote-machi, Chiyoda-ku, Tokyo 100-0004, Japan

E-mail: okuyama.arata@met.kishou.go.jp

J-stage Advance Published Date: 30 March 2018
Imager (AHI), whose observation capability is superior to that of its predecessor MTSAT-series satellites (Bessho et al. 2016). By way of example, the spatial resolution in the MTSAT-2 imager's infrared (IR) band is $4 \mathrm{~km}$ at the subsatellite point (SSP) as compared to $2 \mathrm{~km}$ for the AHI.

The AHI produces Full-Disk imagery every 10 minutes. During these periods, three rapid scans at 2.5-minute intervals and two superrapid scans at 30second intervals are also conducted. Figure 1 shows a typical "timeline", a basic unit for observation schedules, based on a 10-minute Full-Disk repeat cycle. The AHI scans five areas: Full-Disk (images of 


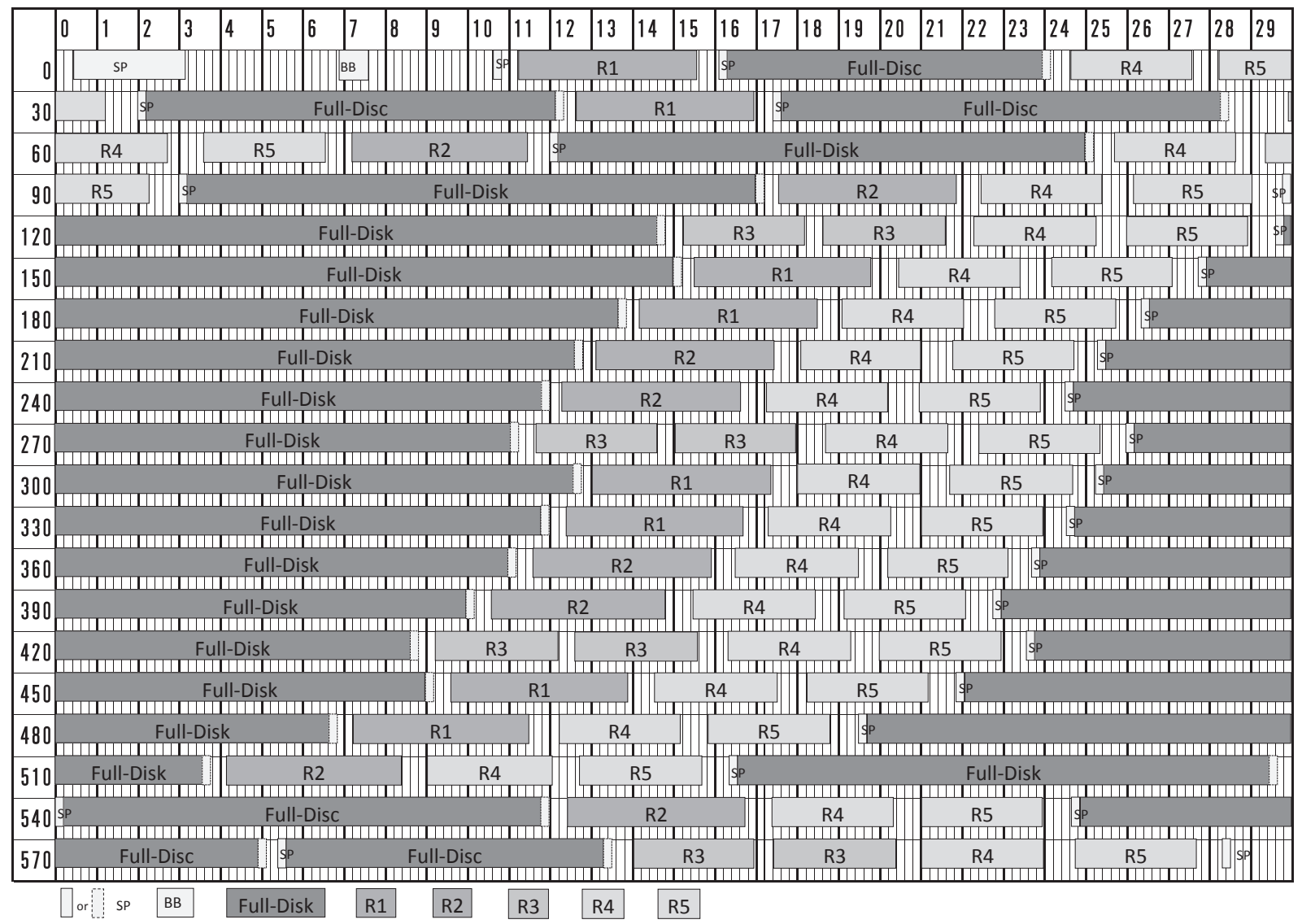

Fig. 1. Typical AHI observation "timeline" for individual 10-minute periods (Okuyama et al. 2015). Rectangles with $\mathrm{R} n$ ( $n=1$ to 5 ) denote regional observation such as that conducted in the Japan Area. Those with BB represent black body observation. Deep-space observation (shown with rectangles marked SP) is performed at the beginning of each timeline and at the beginning or end of each swath for full-disk observation (rectangles marked Full-Disk).

the whole earth as seen from the satellite), the Japan Area (Regions 1 and 2), the Target Area (Region 3), and two Landmark Areas (Regions 4 and 5). While the scan regions for Full-Disk and the Japan Area are predefined, those of the Target Area are flexible to enable prompt reaction to meteorological or nonmeteorological conditions such as typhoons and volcanic activity. The observation regions of Landmark Areas are also flexible, and data collected are generally used along with Full-Disk data to improve image navigation and registration (INR) accuracy. One of the Landmark Areas can also be used to observe the moon for the purpose of radiometric calibration and INR. Based on prior prediction of lunar positions, the AHI can observe the moon up to 20 times during one timeline.

The hardware configuration of the AHI is similar to that of the Advanced Baseline Imager (ABI) aboard the GOES-16 satellite (Schmit et al. 2005, 2008, 2017) and that of the Advanced Meteorological Imager (AMI) aboard the GEO-KOMPSAT-2A satellite (Griffith 2016a), which were manufactured by Harris Corporation (formerly Exelis Inc., which was formerly ITT Geospatial Systems). Table 1 summarizes the characteristics of the AHI, which has 16 observation bands covering visible, shortwave IR, and thermal-IR spectra (Takahashi and Okuyama 2017). The ABI has a $1.38 \mu \mathrm{m}$ band as opposed to the $0.51 \mu \mathrm{m}$ band specification of the AHI. The specifications of the AHIs aboard Himawari-8 and Himawari-9 are identical, but their sensor response functions and other characteristics slightly differ. The wealth of information that can be obtained from multiband observation is advantageous for generating meteorological and climatological products. For instance, such observation enables 
Table 1. Characteristics of the Himawari-8 AHI (Takahashi and Okuyama 2017) based on ground testing. The bandwidth is defined as FWHM (Full width at half maximum), the central wavelength is that of the bandwidth. Radiance values corresponding to $100 \%$ albedo are shown in Table 3. Spatial resolution is the one defined at the SSP.

\begin{tabular}{|c|c|c|c|c|c|c|c|c|}
\hline Band & $\begin{array}{c}\text { Central } \\
\text { wavelength } \\
{[\mu \mathrm{m}]}\end{array}$ & $\begin{array}{l}\text { Band } \\
\text { width } \\
{[\mu \mathrm{m}]}\end{array}$ & $\begin{array}{c}\text { SNR (Band 1-6) } \\
\text { NEdT (Band 7-16) }\end{array}$ & $\begin{array}{l}\text { Dynamic } \\
\text { Range }\end{array}$ & $\begin{array}{l}\text { Detector } \\
\text { number }\end{array}$ & $\begin{array}{l}\text { Detector } \\
\text { redundant } \\
\text { columns }\end{array}$ & $\begin{array}{c}\text { Bit } \\
\text { depth }\end{array}$ & $\begin{array}{c}\text { Spatial } \\
\text { resolution } \\
{[\mathrm{km}]}\end{array}$ \\
\hline 1 & 0.4703 & 0.0407 & 585@100\% albedo & $120 \%$ & 676 & 3 & 11 & 1.0 \\
\hline 2 & 0.5105 & 0.0308 & 645@100\% albedo & $135 \%$ & 676 & 3 & 11 & 1.0 \\
\hline 3 & 0.6399 & 0.0817 & 459@100\% albedo & $165 \%$ & 1460 & 3 & 11 & 0.5 \\
\hline 4 & 0.8563 & 0.0345 & 420@100\% albedo & $205 \%$ & 676 & 6 & 11 & 1.0 \\
\hline 5 & 1.6098 & 0.0409 & 912@100\% albedo & $121 \%$ & 372 & 6 & 11 & 2.0 \\
\hline 6 & 2.2570 & 0.0441 & 688@100\% albedo & $132 \%$ & 372 & 6 & 11 & 2.0 \\
\hline 7 & 3.8848 & 0.2006 & $0.21 @ 300 \mathrm{~K}$ & $401 \mathrm{~K}$ & 332 & 6 & 14 & 2.0 \\
\hline 8 & 6.2383 & 0.8219 & $0.13 @ 240 \mathrm{~K}$ & $317 \mathrm{~K}$ & 332 & 6 & 11 & 2.0 \\
\hline 9 & 6.9395 & 0.4019 & $0.039 @ 300 \mathrm{~K}$ & $327 \mathrm{~K}$ & 332 & 6 & 11 & 2.0 \\
\hline 10 & 7.3471 & 0.1871 & $0.13 @ 240 \mathrm{~K}$ & $327 \mathrm{~K}$ & 332 & 6 & 12 & 2.0 \\
\hline 11 & 8.5905 & 0.3727 & 0.042@300 K & $344 \mathrm{~K}$ & 332 & 6 & 12 & 2.0 \\
\hline 12 & 9.6347 & 0.3779 & $0.052 @ 300 \mathrm{~K}$ & $328 \mathrm{~K}$ & 332 & 6 & 12 & 2.0 \\
\hline 13 & 10.4029 & 0.4189 & 0.077@300 K & $371 \mathrm{~K}$ & 408 & 6 & 12 & 2.0 \\
\hline 14 & 11.2432 & 0.6678 & $0.063 @ 300 \mathrm{~K}$ & $348 \mathrm{~K}$ & 408 & 6 & 12 & 2.0 \\
\hline 15 & 12.3828 & 0.9656 & $0.087 @ 300 \mathrm{~K}$ & $403 \mathrm{~K}$ & 408 & 6 & 12 & 2.0 \\
\hline 16 & 13.2844 & 0.5638 & $0.22 @ 300 \mathrm{~K}$ & $410 \mathrm{~K}$ & 408 & 6 & 11 & 2.0 \\
\hline
\end{tabular}

more precise height assignment in atmospheric motion vector (AMV) retrieval, which plays very important roles in numerical weather prediction (NWP).

The AHI's efficiency in frequent multiband observation supports environmental monitoring and operational weather services. Such observation requires precise multiband image navigation, coregistration, and calibration. For instance, the INR accuracy directly affects the AMV product quality. In addition, Himawari-8/AHI (referred to here as AHI-8) observation data are widely used to generate nonmeteorological information on variables such as sea surface temperature, ocean color, aerosol concentrations, and volcanic ash presence (Commitee on Earth Observation Satellites 2016). JMA began distributing AHI-8 in-orbit test imagery on 8 April 2015 via the HimawariCloud service. In view of the essential nature of navigation and radiometric calibration to fully leverage the AHI's potential, several studies involving commissioning-phase data have been conducted ( $\mathrm{Da}$ 2015; Yu and Wu 2016; Liang et al. 2016; Okuyama et al. 2015). The quality of commissioning-phase data is not always equivalent to that of operational-phase data. The JMA updated the INR and calibration processes several times during the commissioning and operational phases to improve data quality (a history of major updates regarding AHI-8 calibration and INR processes is shown in Table 2). For instance, the east-west (EW) angular sampling distances (ASDs) were 14,28 , and $56 \mu \mathrm{rad}$ for the $0.5,1.0$, and $2.0 \mathrm{~km}$ resolution bands, respectively. On 18 May 2015, the EW-ASDs were changed to 13,26 , and $52 \mu \mathrm{rad}$ to reduce resampling noise in the process of generating level 1b Himawari Standard Data (HSD) (Japan Meteorological Agency 2017a) from level 1a Himawari radiometric data (Bessho et al. 2016). The northsouth ASDs have not been changed. It should be noted that the spatial resolutions of the HSD remain the same $(0.5,1.0$, and $2.0 \mathrm{~km}$ at Himawari- $8 \mathrm{SSP}$ as shown in Table 1) regardless of the EW-ASD change. The signal-to-noise ratio (SNR) and noise-equivalent differential temperature (NEdT) data shown in Table 1 were obtained under this predefined $14 \mu \mathrm{rad}$ condition in prelaunch ground testing.

Major updates implemented on 9 March and 16 November 2016 after the start of operation improved band-to-band coregistration performance and noise characteristics. Tabata et al. (2016) evaluated bandto-band coregistration performance after the update on 9 March 2016, reporting coregistration errors in the order of 0.01 pixels. This analysis was performed with a pattern-matching approach involving the comparison of band images with Band $13(10.4 \mu \mathrm{m})$ images. One pixel corresponds to a distance of $2 \mathrm{~km}$ at the Himawari-8 SSP. This refinement was initially implemented on part of the IR bands (Bands 7 to 12 and 15) and then on all the remaining bands with the second update on 16 November 2016. 
Table 2. History of major updates to the AHI-8 calibration and INR processes as of March 2017. As described in Section 3.2 and 7, reduction process of banding and stripe noise and update of VNIR calibration coefficients in HSD were implemented on 25 July 2017.

\begin{tabular}{|c|c|c|}
\hline Date & Type & Update \\
\hline 16 January 2015 & INR & Attitude correction using landmark start \\
\hline 4 February 2015 & INR & Band-to-band registration process start on Bands 1 to 6 \\
\hline $\begin{array}{l}2,9,10,13 \text {, and } 17 \\
\text { March } 2015\end{array}$ & Calibration & Infrared band calibration process update \\
\hline 26 March 2015 & INR & Band-to-band registration process start on Bands 7 to 16 \\
\hline 18 May 2015 & Calibration & Angular sampling distance update \\
\hline 8 June 2015 & Calibration & Visible and near-infrared band calibration coefficient update \\
\hline 18 June 2015 & Calibration & Noise reduction process activation on Band 7 \\
\hline 9 March 2016 & Calibration, INR & $\begin{array}{l}\text { Noise reduction process activation on Bands } 1,2,4,5,6 \text {, and } 10 \text { to } 15 \\
\text { Band-to-band co-registration process update for Bands } 7 \text { to } 12 \text { and } 15\end{array}$ \\
\hline 16 November 2016 & INR & Band-to-band co-registration process update for Bands 1 to 6,14 , and 16 \\
\hline
\end{tabular}

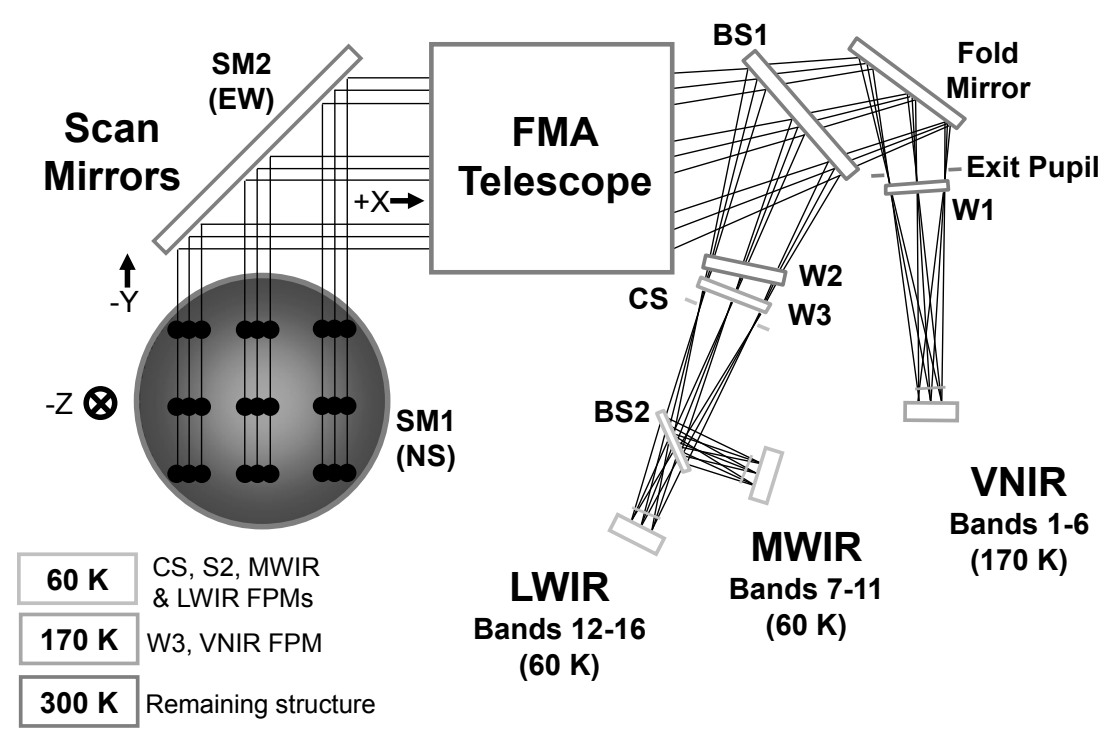

Fig. 2. Conceptual diagram of the AHI optical system (Griffith 2015). SM1 and SM2 show two scan mirrors for the north-south and east-west directions, respectively. VNIR, MWIR and LWIR are the focal plane modules for visible near-infrared, middle wavelength infrared and long wavelength infrared, respectively.

The JMA has validated AHI calibration performance in collaboration with Japanese research agencies and the Global Space-based Inter-Calibration System (GSICS) international satellite data calibration framework (Goldberg et al. 2011) established by the World Meteorological Organization (WMO) and the Coordination Group for Meteorological Satellites (CGMS). This study focused on AH-8 radiometric calibration performance based on around two years of observation data.

\section{On-board calibration system}

\subsection{Structure of the AHI scan system}

Figure 2 illustrates the AHI optical system. The unit has two scan mirrors for east-west and north-south scanning. After passing through a telescope module, incident radiation is split into three paths-visible and near-IR (VNIR), middle-wavelength IR (MWIR), and long-wavelength IR (LWIR) - depending on the wavelength. Polarization sensitivity is canceled around 
the center of the mirrors via double mirror reflection (Griffith 2015). The detector array on a focal-plane module is composed of three or six columns of detectors for redundancy, with each column having hundreds to more than one thousand detectors (Table 1). Operational detectors are selected from one of the three or six detector columns line by line in consideration of detector response performance as determined in prelaunch ground testing and in-orbit testing. One swath is composed of the numbers of detectors shown in Table 1, and 23 swaths from west-east scanning are used to perform Full-Disk observation.

\subsection{Onboard calibration approaches}

For calibration of observation data, the AHI has a blackbody as an internal calibration target (ICT) and a solar diffuser as a solar calibration target (SCT). Using these targets and deep-space observation, a gain and an offset for a quadratic calibration equation are derived to enable conversion of detector-sampled raw data counts into radiances.

The ICT is temperature-controlled using heaters, has very high emissivity $(>0.995)$, and generates NIST-traceable radiance data for IR band calibration (Griffith 2015). This is referred to as warm reference along with space view observation data used as cold reference for IR bands. The AHI observes the ICT every 10 minutes, and deep-space viewing is performed for the eastern or western side of the earth disk (whichever is farther from the sun to avoid potential solar light contamination) for every swath of Full-Disk observation. Detailed sequences of the ICT and deepspace viewing are shown as rectangles marked with BB and SP, respectively, in Fig. 1. The calibration equation for the IR bands is given by Eq. (1) below. $L_{o b s}$ denotes the observed radiance; $C$ is the raw digital count; $q, m$, and $b$ are calibration coefficients; $L_{M n s}$ and $L_{\text {Mew }}$ are emissions from the NS and EW scan mirrors, respectively, as calculated from the scan mirror temperature and the sensor Planck function; and $\theta$ and $\phi$ are the incident angles to the NS and EW scan mirrors, respectively. $\epsilon_{n s}$ and $\epsilon_{e w}$ are the emissivities of the NS and EW scan mirrors as determined at the prelaunch stage. The coefficient $m_{n}$ is updated on the basis of the ICT observation every 10 minutes, and $b_{n}$ is updated on the basis of deep-space observation every Full-Disk swath. The coefficient $q_{n}$ is determined from ground testing at the prelaunch stage. As the coefficients are determined for each detector, $n$ denotes the ID number of each detector.

$$
\begin{aligned}
L_{\text {obs }}= & F(\theta, \phi)\left(q_{n} C^{2}+m_{n} C+b_{n}\right) \\
& -G(\theta) L_{\text {Mns }}-H(\theta, \phi) L_{\text {Mew }},
\end{aligned}
$$

where

$$
\begin{aligned}
F(\theta, \phi) & =\frac{1}{\left(1-\epsilon_{e w}(\phi)\right)\left(1-\epsilon_{n s}(\theta)\right)}, \\
G(\theta) & =\frac{\epsilon_{n s}(\theta)}{1-\epsilon_{n s}(\theta)}, \\
H(\theta, \phi) & =\frac{\epsilon_{e w}(\phi)}{\left(1-\epsilon_{e w}(\phi)\right)\left(1-\epsilon_{n s}(\theta)\right)} .
\end{aligned}
$$

The solar diffuser (SCT) is made of Spectralon manufactured by Labsphere Inc., as is the onboard calibration equipment of the MODerate resolution Imaging Spectroradiometer (MODIS) aboard the Aqua and Terra satellites. The SCT reflects and diffuses sunlight for observation by detectors and is used as a bright reference for VNIR bands together with the space view observation values used as dark references. SCT observation is performed twice a month. The AHI does not carry equipment such as the Solar Diffuser Stability Monitor (SDSM) instrument that is carried by MODIS to monitor SCT degradation. The SCT has a cover to prevent solar light exposure, and each exposure time is around a minute. Bruegge et al. (1993) investigated the characteristics of Spectralon under ultraviolet (UV) exposure over 500 equivalent UV solar hours (EUVSH) and reported that the change in reflectance was $5.1 \%, 1.8 \%, 2.0 \%$, and $0.0 \%$ at Multi-angle Imaging SpectroRadiometer (MISR) wavelengths of $0.443 \mu \mathrm{m}, 0.555 \mu \mathrm{m}, 0.670 \mu \mathrm{m}$, and $0.865 \mu \mathrm{m}$, respectively. Prelaunch analysis with consideration of the total number of SCT observations revealed an SCT degradation level far lower than the AHI's mission requirement and suggested that effective reflected SCT radiation will remain at $100 \%$ ( $\pm 5 \%$ ) of $F_{0}$ throughout the AHI's operational lifetime (Yokota and Sasaki 2013). $F_{0}$ values are shown in Table 3.

The VNIR band calibration equation is given in Eq. (2). $\rho_{n s}$ and $\rho_{e w}$ denote NS and EW scan mirror reflectivity, respectively. The bias term $C_{s p, E a r t h}$ is updated on the basis of the deep-space view swath by swath. Unlike with IR bands, a linear term coefficient, $m_{n}$, is determined on the basis of offline analysis of SCT observation data. The $m_{n}$ value based on ground testing was temporarily used after launch. This was updated on 8 June 2015 to reflect SCT viewing data collected in orbit; specifically, this was the average of 
Table 3. Band-averaged solar spectral radiance at a distance of 1 AU derived using $F_{0} / \pi$, where $F_{0}$ is the bandintegrated spectral irradiance

\begin{tabular}{lcc}
\hline & {$\left[\mathrm{mW} / \mathrm{m}^{2} / \mathrm{sr} / \mathrm{cm}^{-1}\right]$} & {$\left[\mathrm{W} / \mathrm{m}^{2} / \mathrm{sr} / \mu \mathrm{m}\right]$} \\
\hline Band 1 & 14.1794 & 641.5092 \\
Band 2 & 15.6393 & 601.9766 \\
Band 3 & 21.1218 & 519.3457 \\
Band 4 & 22.6929 & 309.3583 \\
Band 5 & 19.9921 & 77.1412 \\
Band 6 & 12.1787 & 23.9163 \\
\hline
\end{tabular}

seven $m_{n}$ values derived from seven SCT observations performed from 7 March to 22 May 2015. As with IR onboard calibration, the prelaunch value of $q$ is used in VNIR onboard calibration.

The radiance for SCT observation is calculated using Eq. (3), where $f_{\text {int }}$ is an integration factor depending on an integration time. A calibration factor $k_{\lambda, n}$ is a fifth-order polynomial of the sun angle parameter on the instrument fixed coordinates $\beta_{\text {eff }}$; $\lambda$ and $n$ denote the numbers of bands and detectors, respectively; $\theta_{\text {sun }}$ is the angle between the sun and the SCT normal vector; and $\left\langle L_{100 \% \alpha, \lambda}\right\rangle$ is the bandaveraged solar spectral radiance based on Kurucz (1995) at a distance of 1 astronomical unit (AU) as shown in Table 3. $R_{\text {sun }}$ and $r$ are the sun-earth distance at $1 \mathrm{AU}$ and at the time of SCT observation, respectively. The calibration slope $m_{n}$ is determined using Eqs. (2) and (3). The integration time for deepspace viewing during SCT observation operation is longer than that for earth observation. Equation (2) is adopted to derive the slope for calibration from SCT observation with different integration times. Due to the difference in these times, $C_{s p, S C T}$ is not necessarily equal to $C_{s p \text { Earth }}$. A similar formulation is also adopted for the ABI calibration process (Datla et al. 2016).

$$
\begin{aligned}
L_{o b s} & =\frac{q_{n} \Delta C^{2}+m_{n} \Delta C}{\rho_{n s} \rho_{e w}} \text { where } \\
\Delta C & =\left\{\begin{array}{c}
C-C_{s p, \text { Earth }}(\text { in Earth obs. }) \\
C-C_{s p, S C T}(\text { in SCT obs. })
\end{array}\right. \\
L_{S C T} & =f_{\text {int }} k_{\lambda, n}\left(\beta_{\text {eff }}\right) \cos \left(\theta_{\text {sun }}\right)\left[\pi\left\langle L_{100 \% \alpha, \lambda}\right\rangle\left(\frac{R_{\text {sun }}}{r}\right)^{2}\right] .
\end{aligned}
$$

Calibrated radiances are converted to two-byte integers using a linear expression and stored as HSD with linear expression coefficients.
2.3 Trend of AHI sensitivity based on SCT observation

Figure 3 shows a time-series representation illustrating the inverse of the calibration slope $1 / \mathrm{m}$ averaged over numerous detectors. $m$ is computed from SCT observation with the assumption of no SCT degradation. Linear regression indicates annual sensitivity degradation of approximately $0.5 \%$ for Bands $1(0.47 \mu \mathrm{m})$ to $4(0.86 \mu \mathrm{m})$ with short-term variations, whereas Bands $5(1.6 \mu \mathrm{m})$ and $6(2.3 \mu \mathrm{m})$ exhibit no clear trend. Sun et al. (2014) reported that the Aqua/ MODIS gain changes for Bands $10(0.488 \mu \mathrm{m}), 13$ $(0.667 \mu \mathrm{m})$, and $17(0.905 \mu \mathrm{m})$ as estimated from solar diffuser analysis are around $-11 \%,+1 \%$, and $+5 \%$ for around 3,000 days after launch (i.e., $-1.3 \%$, $+0.1 \%$, and $+0.6 \%$ per year), respectively. The AHI has no equipment for SCT performance monitoring (e.g., approaches based on SDSM). Assuming that the linear regression in Fig. 3 represents the detectoraveraged sensitivity trend without SCT degradation, shorter wavelength bands tend to show larger sensitivity degradation for both AHI and MODIS. These are generally consistent with the results of other forms of validation for VNIR bands as described in Section 5.3. Further analysis and long-term monitoring are necessary to reduce the remaining seasonal variations shown in Fig. 3.

\section{Image quality}

\subsection{Eclipse season operation and stray light}

MTSAT-series satellites did not perform midnight observation during the equinox season because solar light entering the imager could adversely affect the sensor's calibration quality and occasionally degrade image quality when the sun and earth are in an approximate line with the satellite. The AHI can continue midnight observation during the eclipse season except for a limited region because the sensor has a function by which part of the observation area can be skipped on the basis of prediction of the sun's position and potentially affected areas. Figure 4a shows a Full-Disk midnight image taken during the eclipse season. To avoid solar interference, no observation is performed over the chipped region. The JMA provides solar interference information during the eclipse season on its Meteorological Satellite Center (MSC) website.

AHI images are affected by stray light during nighttime around the eclipse periods from early January to early May and from mid-August to early December, as seen with Bands 1 to 8 (Fig. 4b) (Shao et al. 2016). The imagery in question is recorded from around 13:10 to 15:50 UTC, and its duration/stray-light amplitude exhibits seasonal and temporal variations. 


\section{Inverse of detector-mean calibration slope from Himawari-8/AHI SD Obs}
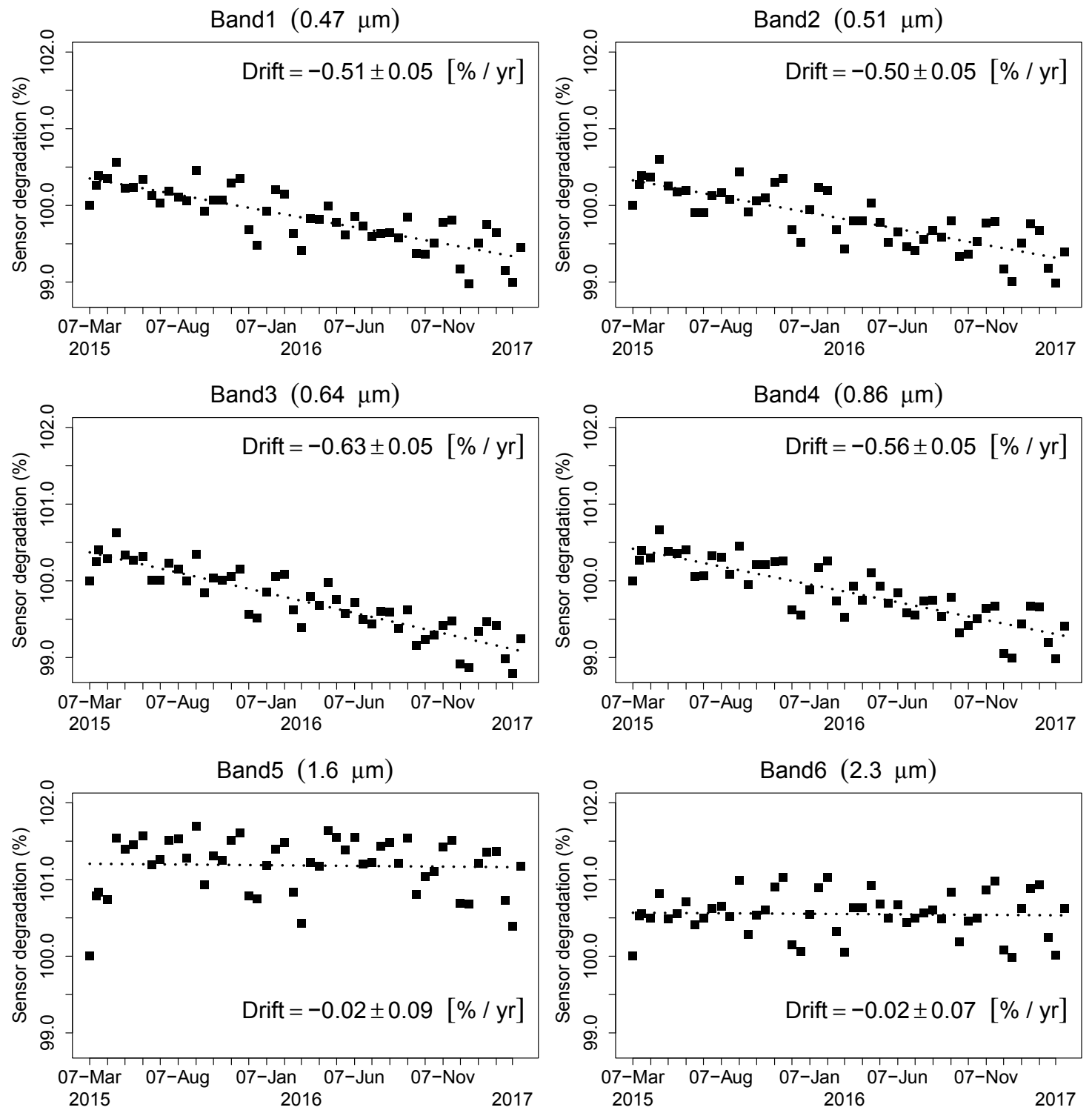

Fig. 3. Time-series representation of the inverse of the calibration coefficient $1 / m$ as computed from SCT observation data (average values for all detectors in each band). The inverses of calibration slopes are normalized with reference to the value for 7 March 2015. A decreasing trend indicates degradation of sensor sensitivity. The uncertainties are standard errors of the regression slopes.

Both the Northern Hemisphere and the Southern Hemisphere are affected. These figures illustrate straylight impacts on shortwave IR bands that could affect L2 product quality. The east-west stripe in Fig. 4b corresponds to the relevant swath widths. Temporal variations in the effects of stray light are described in Section 6.

\subsection{Striping, banding, and coherent noise}

Current AHI- 8 images are also affected by detectorto-detector striping, banding, coherent noise, and other influences. Detector-to-detector striping is brought about by relative calibration differences between adjacent detectors. Murakami (2016) reported that a bandlike structure with a width corresponding to individual 

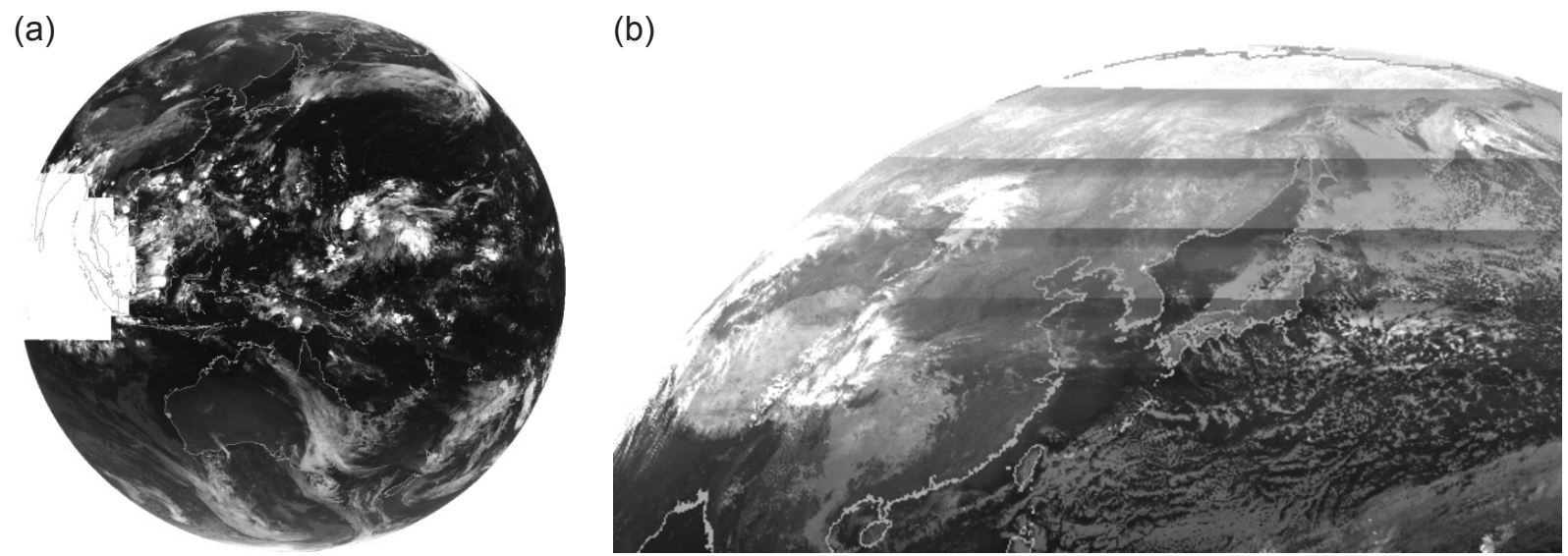

Fig. 4. a) Band 13 Full-disk midnight image captured during the eclipse season (13:50 UTC, 20 September 2016); b) stray light in Band 7 (14:50 UTC, 14 February 2017).

swaths is observed in the AHI-8 ocean color product. The ocean color product is based on the clear-sky ocean region of visible bands and requires a higher SNR than typical meteorological applications targeting clouds. This banding, which did not conflict with AHI specifications, was mainly caused by incorrect calibration slopes derived from SCT observation data; the bidirectional reflectance distribution function (BRDF) of the AHI-8 solar diffuser underwent an erroneous reversal from the north to the south during the calibration slope derivation. This was fixed, and corrected VNIR calibration information has been included in AHI-8 HSD since 25 July 2017 (Japan Meteorological Agency 2017b). In addition, all AHI bands exhibit a type of coherent noise manifesting as vertical stripes in low-radiance scenes (Griffith 2016b). The JMA implemented a noise reduction process for Band 7 on 18 June 2015 and for Bands 1, 2, 4, 5, 6, and 10-15 on 9 March 2016 to improve image signal-to-noise characteristics.

\section{Postlaunch calibration validation for IR bands}

\subsection{Approach}

An IR calibration approach developed under the GSICS framework involves the use of hyperspectral infrared sounders (a.k.a. hypersounders) aboard low-earth-orbit (LEO) satellites (e.g., the Infrared Atmospheric Sounding Interferometer (IASI) on EUMETSAT's Metop satellite and the Atmospheric InfraRed Sounder (AIRS) on NASA's Aqua satellite) as reference sensors (Gunshor et al. 2006; Tobin et al. 2009; Hewison et al. 2013). Intercalibration based on the GSICS method described by Hewison et al. (2013) for GEO satellites such as MTSAT-2 is summarized below.

Step 1: Subsetting

A subset of GEO and LEO data from around the SSP of the GEO satellite is extracted to provide candidates for collocation data to be processed in the next step. In the study of this AHI, the Crosstrack InfraRed Sounder (CrIS) on the Suomi National Polar-orbiting Partnership (S-NPP) satellite, the IASIs on Metop-A/Metop-B, and AIRS were utilized as reference sensors. The target instrument for monitoring is the AHI.

Step 2: Collocating

Spatially and temporally close GEO and LEO data samples are selected from the data subset. The selected values, which have similar observation times and geometrically close satellite zenith angles, are referred to as collocation data.

First, AHI pixels are averaged on a $7 \times 7$ basis for comparison with the LEO spatial resolution (i.e., fields of view covering 13.5, 12, and $14 \mathrm{~km}$ for AIRS, IASI, and CrIS, respectively). Pixels not satisfying the following are screened out:

$$
\begin{aligned}
& \left|\begin{array}{l}
\text { AHI_observation_time } \\
- \text { LEO_observation_time }
\end{array}\right|<300 \mathrm{~s} . \\
& \left|\frac{\cos (\text { LEO_satellite_zenith_angle })}{\cos (\text { GEO_satellite_zenith_angle })}-1\right|<\max \text { _zen. }
\end{aligned}
$$

For AHI, a threshold value of max_zen $=0.03$ is used for cloudy scenes of Bands 7, 11, 12, 13, 14, 15 , and 16. A value of 0.01 is used for clear scenes 
of these bands and all-weather conditions for water vapor bands (i.e., Bands 8, 9, and 10). For simplicity, the $\mathrm{Tb}$ of $275 \mathrm{~K}$ for Band 13 is used as the threshold for clear/cloudy weather condition categorization.

Step 3: Transforming

A superchannel cloning the broad band of the GEO imager is generated from the convolution of hypersounder data. In cases where a GEO imager's band is not fully covered by the hypersounders' spectral bands, the missing spectral domain is simulated using the spectral compensation method (Tahara and Kato 2009).

\section{Step 4: Filtering}

To mitigate random errors caused by image navigation errors or by optical path differences between GEO and LEO satellites, spatially uniform collocation data are adopted.

Step 5: Monitoring

The brightness temperature $(\mathrm{Tb})$ bias of the monitored GEO imager is derived from weighted linear regression of the collocation data. The JMA monitors and publishes bias information based on daily and near-monthly statistics on its website (https:// www.data.jma.go.jp/mscweb/data/monitoring/calibration.html).

Step 6: Correcting

The regression coefficients described in Step 5 (referred to as GSICS Corrections) can be used to correct the radiance of the sensor being monitored for consistency with reference values. GSICS Corrections are available on the JMA/MSC website and on GSICS Collaboration Servers operated within the GSICS framework.

Step 7: Diagnosing

The root causes of biases and sensor trends are identified from intercalibration results and reported. Tb biases determined using this intercalibration approach on a half-hourly basis, for example, revealed unexpected diurnal variations of $\mathrm{Tb}$ biases during AHI-8's early commissioning phase (as described later). The JMA found that the variation was caused by incorrect blackbody calibration in the ground processing system, and the issue was promptly fixed.

$\mathrm{Tb}$ biases are estimated in consideration of the differences between corrected and reference $\mathrm{Tb}$ values. The corrected $\mathrm{Tb}$ is converted from the corrected radiance derived in Step 6. As this approach could result in scene-dependent $\mathrm{Tb}$ biases related to the scenedependent radiance correction coefficients derived in Step 5 and Plank's Law, which involves a nonlinear
Table 4. Tb biases in AHI-8 IR bands at standard radiances $[\mathrm{K}]$, with related uncertainties $[\mathrm{K}]$, standard error $(=$ coverage factor is 1), in brackets. The statistical period covers 29 days centered on 15 July 2015. N/A represents bands not inter-calibrated due to a wide spectral gap between AHI- 8 and hyper sounder data, such as CrIS coverage of only the edge of the SRF for AHI-8 Band 11.

\begin{tabular}{|c|c|c|c|c|c|}
\hline \multirow{2}{*}{ Band } & \multirow{2}{*}{$\begin{array}{c}\text { Standard } \\
\text { TB }[\mathrm{K}]\end{array}$} & \multicolumn{4}{|c|}{ TB bias at standard radiance $[\mathrm{K}]$} \\
\hline & & IASI/A & IASI/B & AIRS & CrIS \\
\hline $\begin{array}{l}\text { Band7 } \\
(3.9 \mu \mathrm{m})\end{array}$ & 285.95 & $\begin{array}{c}-0.10 \\
(0.004)\end{array}$ & $\begin{array}{c}-0.09 \\
(0.004)\end{array}$ & $\begin{array}{c}-0.02 \\
(0.004)\end{array}$ & N/A \\
\hline $\begin{array}{l}\text { Band8 } \\
(6.2 \mu \mathrm{m})\end{array}$ & 234.65 & $\begin{array}{c}-0.16 \\
(0.004)\end{array}$ & $\begin{array}{c}-0.16 \\
(0.004)\end{array}$ & N/A & $\begin{array}{c}-0.14 \\
(0.003)\end{array}$ \\
\hline $\begin{array}{l}\text { Band9 } \\
(6.9 \mu \mathrm{m})\end{array}$ & 243.85 & $\begin{array}{c}-0.20 \\
(0.004)\end{array}$ & $\begin{array}{c}-0.20 \\
(0.005)\end{array}$ & $\begin{array}{c}-0.30 \\
(0.004)\end{array}$ & $\begin{array}{c}-0.22 \\
(0.003)\end{array}$ \\
\hline $\begin{array}{c}\text { Band10 } \\
(7.3 \mu \mathrm{m})\end{array}$ & 254.59 & $\begin{array}{c}-0.11 \\
(0.004)\end{array}$ & $\begin{array}{c}-0.13 \\
(0.004)\end{array}$ & $\begin{array}{c}-0.18 \\
(0.003)\end{array}$ & $\begin{array}{c}-0.14 \\
(0.003)\end{array}$ \\
\hline $\begin{array}{l}\text { Band11 } \\
(8.6 \mu \mathrm{m})\end{array}$ & 283.82 & $\begin{array}{c}-0.03 \\
(0.003)\end{array}$ & $\begin{array}{c}-0.03 \\
(0.004)\end{array}$ & N/A & N/A \\
\hline $\begin{array}{l}\text { Band12 } \\
(9.6 \mu \mathrm{m})\end{array}$ & 259.45 & $\begin{array}{c}-0.20 \\
(0.004)\end{array}$ & $\begin{array}{c}-0.14 \\
(0.005)\end{array}$ & $\begin{array}{c}-0.21 \\
(0.004)\end{array}$ & $\begin{array}{c}-0.20 \\
(0.003)\end{array}$ \\
\hline $\begin{array}{l}\text { Band13 } \\
(10.4 \mu \mathrm{m})\end{array}$ & 286.18 & $\begin{array}{c}0.06 \\
(0.004)\end{array}$ & $\begin{array}{c}0.09 \\
(0.004)\end{array}$ & $\begin{array}{c}0.05 \\
(0.004)\end{array}$ & $\begin{array}{c}0.01 \\
(0.003)\end{array}$ \\
\hline $\begin{array}{c}\text { Band14 } \\
(11.2 \mu \mathrm{m})\end{array}$ & 286.10 & $\begin{array}{c}0.07 \\
(0.004)\end{array}$ & $\begin{array}{c}0.10 \\
(0.004)\end{array}$ & $\begin{array}{c}-0.01 \\
(0.004)\end{array}$ & $\begin{array}{c}0.02 \\
(0.003)\end{array}$ \\
\hline $\begin{array}{c}\text { Band15 } \\
(12.4 \mu \mathrm{m})\end{array}$ & 283.78 & $\begin{array}{c}-0.01 \\
(0.004)\end{array}$ & $\begin{array}{c}0.02 \\
(0.004)\end{array}$ & $\begin{array}{c}-0.01 \\
(0.004)\end{array}$ & $\begin{array}{c}-0.07 \\
(0.003)\end{array}$ \\
\hline $\begin{array}{c}\text { Band16 } \\
(13.3 \mu \mathrm{m})\end{array}$ & 269.73 & $\begin{array}{c}0.10 \\
(0.003)\end{array}$ & $\begin{array}{c}0.14 \\
(0.003)\end{array}$ & $\begin{array}{c}0.10 \\
(0.003)\end{array}$ & $\begin{array}{c}0.04 \\
(0.003)\end{array}$ \\
\hline
\end{tabular}

relationship between radiance and temperature, this paper describes sensor bias at a standard radiance defined by GSICS as the Tb of a typical observation scene and computed using RTTOV-11.2 for a 1976 US Standard Atmosphere at nadir, at night, in clear sky, and over the ocean with an SST of $288.15 \mathrm{~K}$ and a wind speed of $7 \mathrm{~m} \mathrm{~s}^{-1}$.

\subsection{Results}

Table 4 summarizes the Tb biases of all AHI- 8 IR bands for the standard scenes. With the reference hypersounders, both daytime and nighttime data are utilized except for Band 7 which contains solar radiation during the daytime. Bands 7,8 , and 11 are not validated using AIRS and/or CrIS because these hypersounders feature wide spectral gaps for those bands. Such gaps could cause a nonnegligible uncertainty in $\mathrm{Tb}$ bias estimation even with the application of the spectral gap-filling method (Tahara and Kato 2009). The estimated biases are within $0.3 \mathrm{~K}$ for all AHI- 8 IR bands and have remained stable since the 

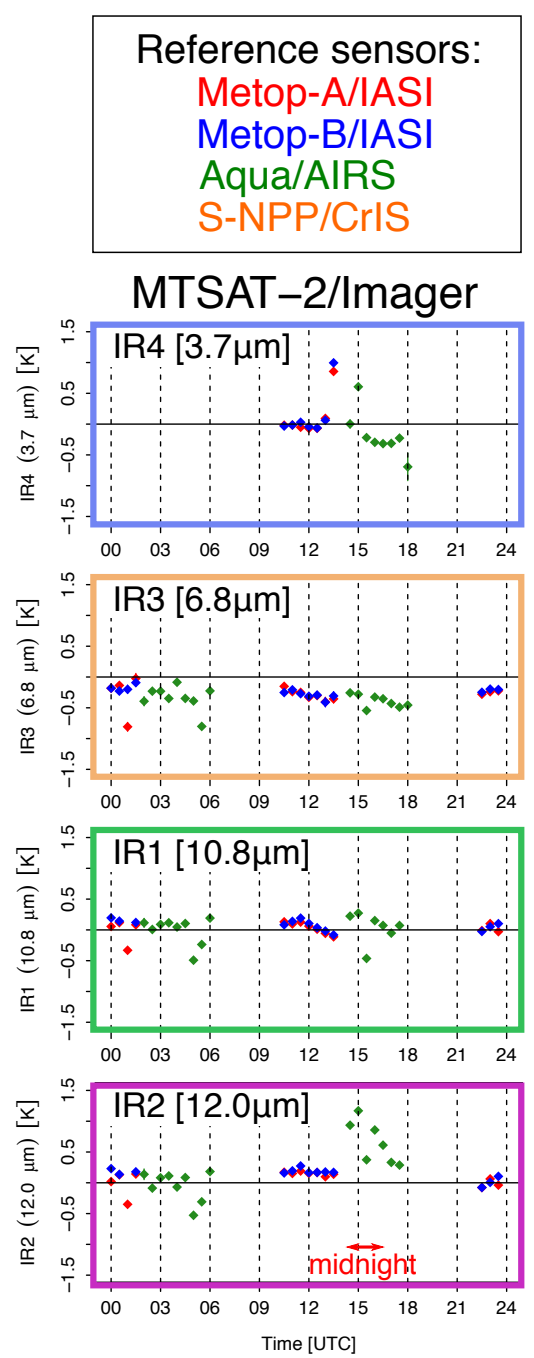
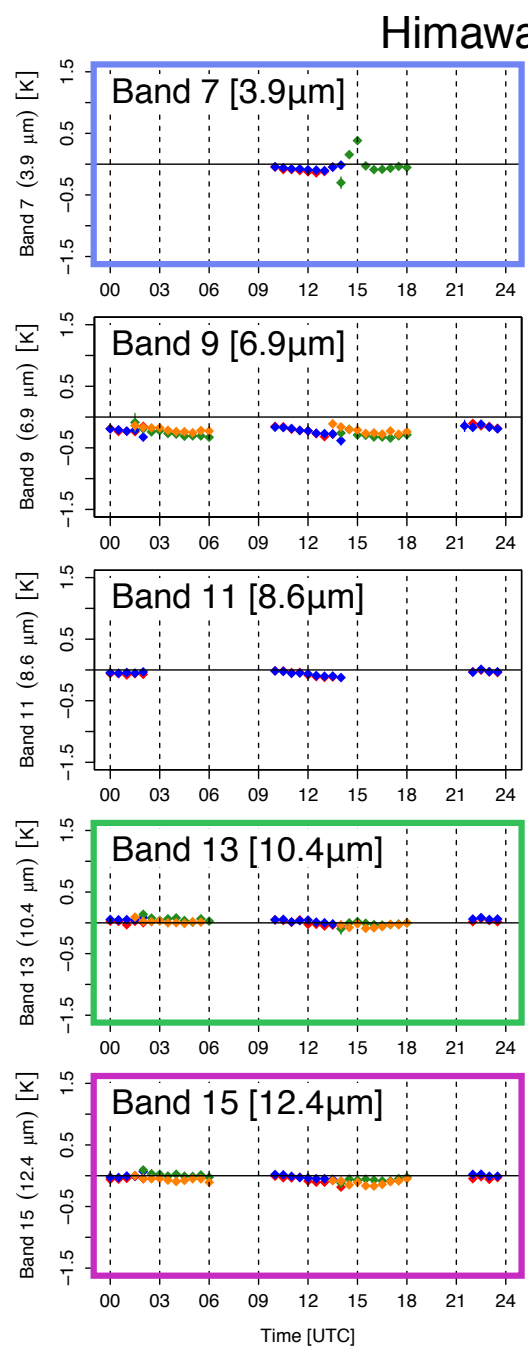
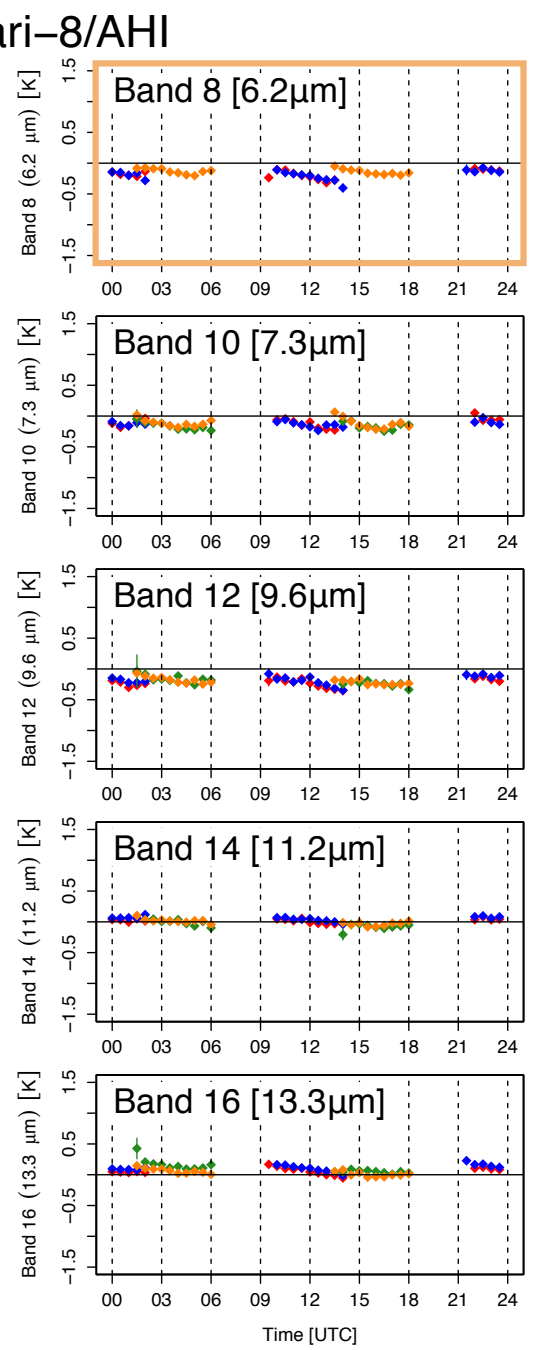

Fig. 5. Time dependence of $\mathrm{Tb}$ biases at the standard radiance between hyper sounders and AHI-8 (right) and MTSAT-2/IMAGER (left) for February 2016. The reference hyper sounders are Aqua/AIRS, Metop-A/IASI, Metop-B/IASI and S-NPP/CrIS. The error bars, which are too short to see, are standard errors of the Tb bias. Colored frames represent corresponding bands which have close characteristics between AHI- 8 and MTSAT-2/ IMAGER based on (Murata et al. 2015).

commissioning phase.

Figure 5 shows the time dependence of $\mathrm{Tb}$ bias between the MTSAT-2 imager (left) and the AHI-8 (right) with reference to hypersounder data. The biases at the standard radiance in each 30-minute time bin are estimated using the intercalibration approach described above. Biases of some MTSAT-2 channels (e.g., 12.0 $\mu \mathrm{m}$ IR2) tend to increase to $1.5 \mathrm{~K}$ at nighttime around the eclipse season, whereas those seen during the daytime are a tenth of these values. Yu et al. (2013) characterized the diurnal variation of $\mathrm{Tb}$ biases for
GOES-11/GOES-12 imagers which carry a similar imager to the one aboard MTSAT-2. AHI- 8 has no significant diurnal variation, although minor variations are observed in several bands.

Application of this approach helped reveal erroneous ground processing as described in Section 4.1 Step 7. Figure 6 illustrates the unexpected diurnal variation of the Band $16 \mathrm{~Tb}$ bias at the standard radiance. The variation was seen in all IR bands during AHI-8's early commissioning phase. 


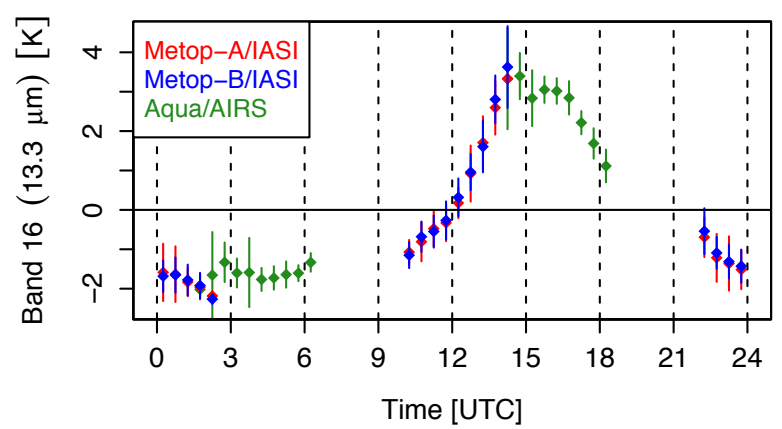

Fig. 6. Time dependence of Band $16 \mathrm{~Tb}$ biases [K] at the standard radiance between hyper sounders and AHI-8 for February 2015 (early commissioning phase). The reference hyper sounders are Aqua/AIRS, Metop-A/IASI and Metop-B/IASI (Takahashi 2016). Error bars represent standard errors of $\mathrm{Tb}$ biases at the standard radiance. Times are UTC, with 15:00 being local midnight for Himawari-8 (e.g., 00:00 LST; Local Sun Time) in Japan.

\section{Postlaunch calibration validation for VNIR bands}

The postlaunch AHI calibration and validation methods outlined below have been developed in collaboration with research organizations in Japan and with GSICS. (A) and (B) are already utilized to monitor AHI-8's calibration performance, and the latter two approaches are under evaluation. This paper focuses on approaches (A) and (B), and the others will be described in the future.

(A) Ray-matching approach with reference to S-NPP/ Visible Infrared Imaging Radiometer Suite (VIIRS)

(B) Radiative transfer calculation (RTC) approach involving comparison with simulated top-of- atmosphere (TOA) radiance

(C) Deep convective cloud (DCC) approach based on Aqua/MODIS data

(D) Lunar irradiance approach involving comparison with lunar model data

\subsection{Ray-matching approach with reference to S-NPP/VIIRS}

The reflective solar bands (RSBs) of the VIIRS aboard S-NPP are well calibrated, and the validated radiometric uncertainties are within $2 \%$, which is comparable to those of MODIS Collection 6 data (Xiong et al. 2016). As VIIRS Spectral Response Functions (SRFs) are also similar to AHI SRFs (Fig. 7), the VIIRS Sensor Data Record (SDR) received from NOAA/NESDIS CLASS is used as a reference for intercalibration of AHI-8 VNIR bands. Collocation datasets of VIIRS and AHI radiances with similar geometric conditions and observation times are used for intercalibration. Based on the Algorithm Theoretical Baseline Document (Doelling et al. 2011, 2013), the collocation conditions of this study involved an observation time difference within five minutes and differences of solar zenith angles, viewing zenith angles, and relative azimuth angles within 10 degrees. Only a cloudy scene is currently adopted because AHI-8 VNIR reflectance in low-radiance scenes does not closely match VIIRS observation data (Yu and $\mathrm{Wu}$ 2016). SRF differences are taken into account in VIIRS radiances via multiplication using Spectral Band Adjustment Factors (SBAFs). This study applied the SBAFs developed by Scarino et al. (2016) for Bands 1-5. These were derived from the Envisat Scanning Imaging Absorption Spectrometer for Atmospheric Chartography (SCIAMACHY) data based on convolution of observations for AHI and VIIRS SRFs. As the SCIAMACHY data available in NASA's SBAF tool (https://www-pm.larc.nasa.gov/SBAF) are limited to the spectral range of $0.24-1.75 \mu \mathrm{m}$, the factor

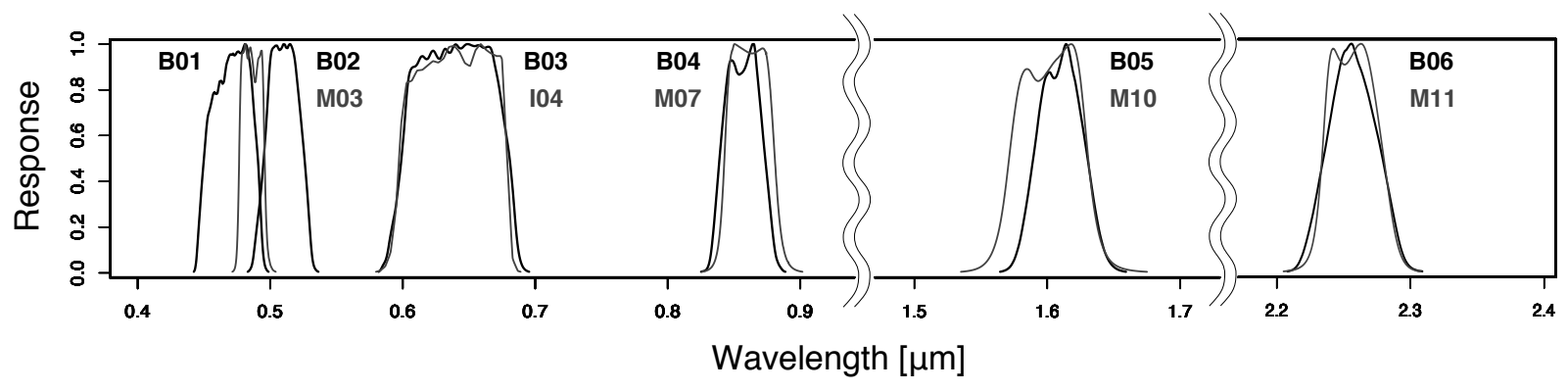

Fig. 7. SRFs of AHI-8 VNIR bands (thick black curves) and S-NPP/VIIRS RSBs (thin gray curves). 
Table 5. SBAF values and reference VIIRS band names for each AHI-8 band. The SBAF values were derived from the conditions with "VIIRS-NG" SRF over the all-sky tropical ocean.

\begin{tabular}{ccccccc}
\hline AHI & $\begin{array}{c}\text { Band 1 } \\
(0.47 \mu \mathrm{m})\end{array}$ & $\begin{array}{c}\text { Band 2 } \\
(0.51 \mu \mathrm{m})\end{array}$ & $\begin{array}{c}\text { Band 3 } \\
(0.64 \mu \mathrm{m})\end{array}$ & $\begin{array}{c}\text { Band 4 } \\
(0.86 \mu \mathrm{m})\end{array}$ & $\begin{array}{c}\text { Band 5 } \\
(1.6 \mu \mathrm{m})\end{array}$ & $\begin{array}{c}\text { Band 6 } \\
(2.3 \mu \mathrm{m})\end{array}$ \\
\hline \multirow{2}{*}{ VIIRS } & $\begin{array}{c}\text { M03 } \\
(0.49 \mu \mathrm{m})\end{array}$ & $\begin{array}{c}\text { M03 } \\
(0.49 \mu \mathrm{m})\end{array}$ & $\begin{array}{c}\text { I04 } \\
(0.64 \mu \mathrm{m})\end{array}$ & $\begin{array}{c}\text { M07 } \\
(0.87 \mu \mathrm{m})\end{array}$ & $\begin{array}{c}\text { M10 } \\
(1.61 \mu \mathrm{m})\end{array}$ & $\begin{array}{c}\text { M11 } \\
(2.25 \mu \mathrm{m})\end{array}$ \\
\hline SBAF & 1.035 & 0.950 & 0.997 & 1.009 & 1.002 & 1.000 \\
\hline
\end{tabular}

for AHI-8 Band 6 is derived from RTC. The SBAF values derived from the conditions with "VIIRS-NG (Northrop Grumman)" SRF over the all-sky tropical ocean and reference VIIRS band names are shown in Table 5.

\subsection{RTC approach involving comparison with simulated TOA radiance}

This vicarious calibration method is based on the comparison of the observed AHI- 8 reflectivity with the simulated AHI- 8 reflectivity at the TOA over pseudoinvariant targets such as cloud-free ocean, cloudfree bare-soil areas, uniform liquid cloud top, and DCC top. RTC requires information on atmospheric profiles, total column ozone amount, surface reflectivity, optical parameters of scattering particles such as clouds or aerosols, and viewing geometry. Atmospheric profiles and ozone amounts are based on JMA's NWP model output (i.e., JRA-55; Kobayashi et al. 2015) and the Aura/OMI L3 product provided by NASA, respectively. RSTAR (Nakajima and Tanaka 1986, 1988; Stamnes et al. 1988) is employed as the radiative transfer code. The optical parameters of scattering particles, such as optical thickness and cloud particle effective radius, are retrieved from Aqua/MODIS L1B Collection 6 data because Terra/ MODIS has a solar diffuser door anomaly that affects its visible band calibration performance (Erives et al. 2004). The cloud and aerosol retrieval systems, "Retrieval of Aerosol Optical Properties (REAP)" (Higurashi et al. 2000; Higurashi and Nakajima 1999; Nakajima and Higurashi 1998; Higurashi 1998) and "Comprehensive Analysis Program for Cloud Optical Measurement (CAPCOM)" (Nakajima and Nakajima 1995; Kawamoto et al. 2001), are based on RSTAR. This validation approach, which involves the use of the same radiative transfer model through the retrieval-and-forward process, reduces RTC uncertainties. A significant advantage is that the accuracy of such retrieved optical parameters themselves is not critical to calibration results because most systematic biases are canceled out through the retrieval-and-forward process even if minor RTC biases exist.

This approach was developed for MTSAT-series satellites and GMS-5 in collaborative research with the Atmosphere and Ocean Research Institute (AORI) at the University of Tokyo. Validation for AHI examines simulation over cloud-free ocean surface and uniform liquid cloud top as calibration targets, as RTC over these targets is more accurate than over other calibration targets. For instance, calculation over cloudfree bare-soil areas requires accurate ground BRDF information, but it is challenging to find ideal areas around the SSP of JMA's GEO satellites. DCC is also a potential target as the brightest radiance for the visible domain, and preliminary studies have been carried out with a simple assumption of cloud ice properties (Kosaka et al. 2012; Japan Meteorological Agency 2013). For the computation of more reliable and stable TOA radiances, the accurate scattering phase function of ice clouds (Letu et al. 2016; Ishimoto et al. 2013) will be taken into account in the RTC approach over $\mathrm{DCC}$ as an AHI calibration target in the future.

\section{a. Liquid cloud top target}

DCCs that reach the tropopause, where atmospheric effects on satellite observation are minimal, are pseudoinvariant calibration targets acting as solar diffusers (Doelling et al. 2013). However, as the RTC scheme for areas over DCCs remains under development, cloud top with liquid cloud particles was adopted as a calibration target in this study. This is mainly because the particle shape is a simple sphere and the calculation algorithm is well established.

The cloud optical thickness and effective radius are from Aqua/MODIS L1B data using the CAPCOM cloud analysis package, which retrieves such cloud optical parameters from visible, near-infrared (NIR), and thermal-IR (TIR) bands of satellite data. Although data from NASA's MODIS cloud product (e.g., MYD06) could serve as an alternative to CAPCOMretrieved cloud parameters for input in forward calculation, the radiative transfer codes used in MYD06 are not consistent with those used in the forward process- 
ing of this vicarious calibration. As look-up table data embedded in CAPCOM are created using RSTAR and assuming vertically uniform and monomodal cloud particle size distribution, JMA's approach involves the use of CAPCOM-retrieved cloud parameters rather than MYD06. In this study, MODIS Band 1 and Band 31 data were adopted as inputs of visible and TIR bands. Nakajima et al. (2010a, b) pointed out that the retrieved cloud particle size parameter depends on the choice of the NIR band, because the shorter wavelength NIR light generally penetrates deeper into the cloud layer because of the smaller imaginary part of the refractive index and the actual cloud droplet size distribution is not always vertically uniform. For more accurate TOA radiance derivation via the retrieval-and-forward process, NIR band input to CAPCOM, which has a wavelength close to that of validated AHI NIR band data, is preferable. This study involved the use of MODIS Band $20(3.750 \mu \mathrm{m})$ data for validation of AHI Bands 1-4 and the use of MODIS Band 7 $(2.130 \mu \mathrm{m})$ data for AHI Band $5(1.6 \mu \mathrm{m})$ and Band $6(2.3 \mu \mathrm{m})$. MODIS Band $6(1.64 \mu \mathrm{m})$ is preferable to MODIS Band 7 for validation of AHI Band 5, but most detectors for Band 6 on Aqua/MODIS are nonfunctional. To enable the estimation of the discrepancy between MODIS Band 7 and Band 6 for the validation of AHI Band 5, the retrieval-and-forward process was applied to AHI Band 5 using Terra/MODIS for the period from July 2015 to February 2017. As mentioned previously, Terra/MODIS VNIR band absolute calibration is affected by the SD door anomaly. However, the relative calibration relationships observed among MODIS bands were considered potentially supportive for this investigation. The simulated TOA radiance for MODIS Band 6 is $2.4 \%$ lower on average than for Band 7.

To support the pick-up of collocation data from MODIS and AHI data, solar/viewing zenith angles are set at less than 60 degrees, and the relative azimuth angle between the AHI and MODIS is set at less than 90 degrees. Sun glint regions are also removed. Uniformity checking is also applied. AHI reflectivities are averaged in $0.02 \times 0.02$-degree grids, and grids with large standard deviations are screened out. As optically thin clouds could increase the simulated TOA radiance uncertainty due to the reflection of solar radiation from the ground surface through clouds, only clouds with an optical thickness greater than 10 are selected. An absence of stratospheric aerosol was assumed in this study because clouds are the dominant source for TOA radiance with this cloud target. The purpose here was to simulate TOA radiance accurately through the retrieval-and-forward process rather than retrieving cloud optical parameters accurately. Under these conditions, the maximum uncertainties in TOA reflectivity biases in 2016 were $4.0 \%, 3.8 \%, 3.6 \%$, $3.7 \%, 2.1 \%$, and $1.9 \%$ for AHI- 8 Bands $1-6$, respectively, where reflectivity is defined by $A=L \pi / F_{0}$ and $L$ represents radiance. These values are monthly standard deviations of simulation minus observation.

\section{b. Clear-sky ocean target}

Ocean surface wind speed and aerosol optical parameters are dominant factors in simulated reflectivity over cloud-free ocean surface areas. As previously stated, sea surface wind speed is derived from JRA-55/JCDAS. Aerosol optical parameters are retrieved from MODIS L1B Band $1(0.645 \mu \mathrm{m})$ and Band $2(0.858 \mu \mathrm{m})$ data using the REAP retrieval tool. The retrieved optical thickness and particle effective radius data are used for forward calculation. Aerosol model parameters such as the refractive index and particle size distribution are based on Higurashi and Nakajima (2002). To remove cloudy or volcanic ash samples and suppress simulation uncertainties, the following conditions are applied in addition to geometrical conditions for target collocation being made the same as those for liquid cloud top targets:

- The Tb of MODIS Band $31(11.03 \mu \mathrm{m})$ must be larger than that of Band $32(12.02 \mu \mathrm{m})$.

- The reflectivity of MODIS Band 1 must be less than 0.1 and higher than that of Band 2.

To derive reliable TOA radiance over cloud-free ocean surface targets for shorter wavelengths, waterleaving radiance and polarization effects need to be considered. As these influences have yet to be taken into account in the TOA radiance calculation for AHI Band $1(0.47 \mu \mathrm{m})$ and Band $2(0.51 \mu \mathrm{m})$, the calculation results are used only for validation of AHI Bands $3-6$.

As with the discussion of the uncertainties outlined in Section 5.2.a, the maximum uncertainties for cloudfree ocean surface targets are estimated as $0.3 \%$, $0.3 \%, 0.2 \%$, and $0.2 \%$ for AHI- 8 Bands 3-6, respectively.

The clear-sky ocean target covers dark scenes, and the RTC approach for this target provides information on radiance biases at lower radiance. In regard to comparison of the ray-matching and RTC approaches described at the beginning of the next subsection, the RTC approach employed only the liquid cloud top target to compare both approaches with the same radiance dynamic range. 


\subsection{Calibration performance for VNIR bands}

Figure 8 shows the trend of calibration performance for AHI-8 as validated using the ray-matching and RTC approaches. As described in Section 5.2, the liquid cloud top target is only used in the latter approach. Vertical dashed lines represent the timing of the calibration coefficient updates detailed in Table 2 for 8 June 2015. The observation values became similar to the reference after the update, especially for Bands 3 and 6 . The ratios estimated using both approaches are close to 1.0 for Bands $1-4$, and there is a discrepancy of around $5 \%$ with respect to a ratio of 1.0 for Bands 5 and 6 (Table 6). The root cause of the discrepancy is under investigation. The discrepancy between both approaches in Band 5 can be explained by nonoptimal and unavoidable Aqua/MODIS band selection as detailed in Section 5.2.a. Other possible causes include the difference in solar irradiance models applied to the onboard calibration process for AHI and VIIRS, SBAF bias in the ray-matching approach possibly related to an unsuitable choice of conditions for SBAF derivation, and an error in the retrieval-and-forward step in the RTC approach related to the wavelength difference between $\mathrm{AHI}$ and MODIS bands. Aqua/MODIS L1B Collection 5 (C5) is utilized in the results with the RTC approach in
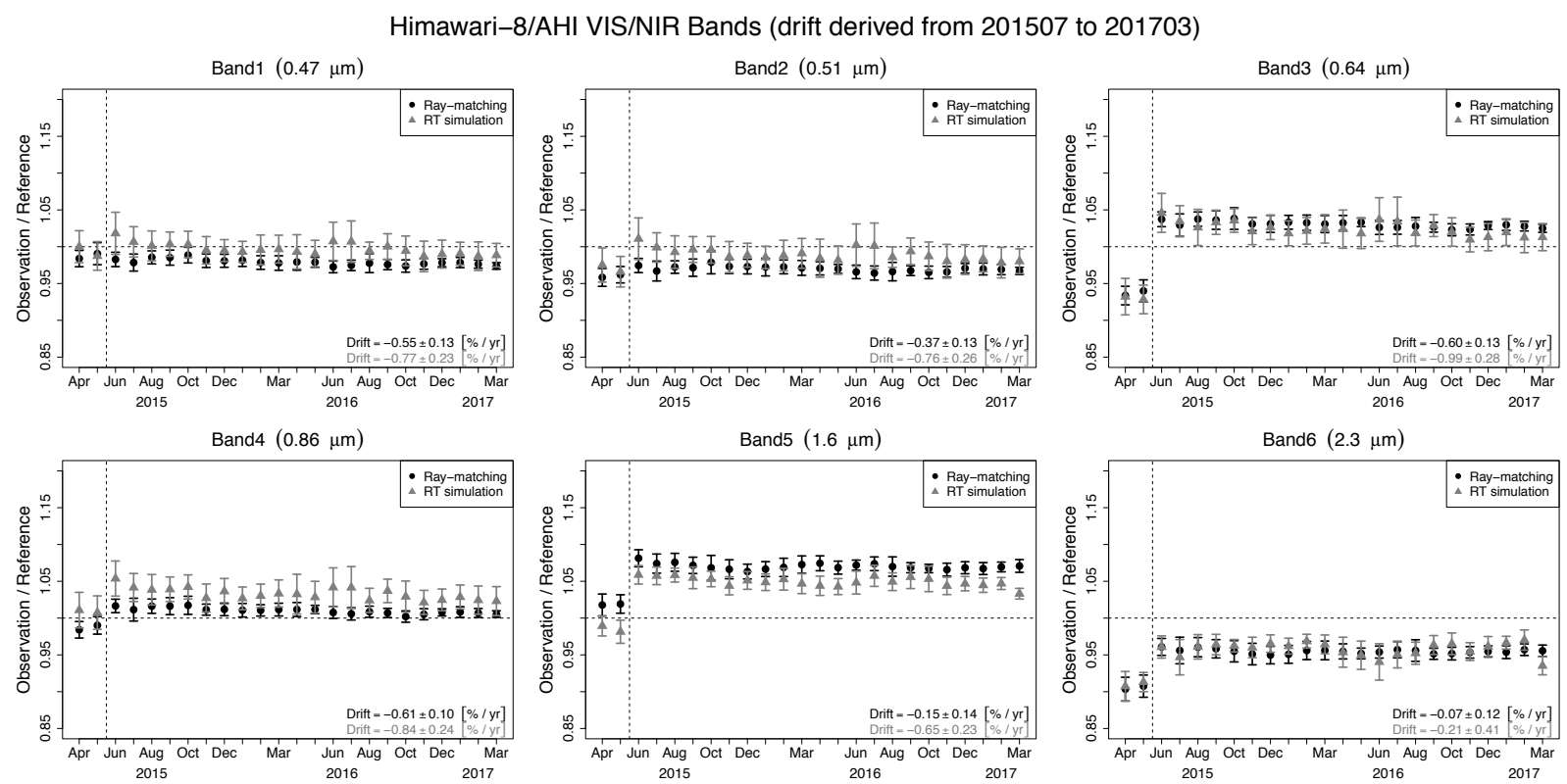

Fig. 8. Trend of the ratio of observation to reference computed using the ray-matching approach (circles) and the RTC approach (triangles). Circles and triangles are monthly averages, and error bars show monthly standard deviations of the daily ratio. Validation trends (e.g., Drift $=\ldots\left[\% \mathrm{yr}^{-1}\right]$ ) are derived from linear regression using results from after July 2015. The uncertainty values at the bottom right in the trends are standard errors of regression slopes. Vertical dashed lines represent the timing of calibration coefficient updates applied on 8 June 2015 .

Table 6. Monthly mean of the observation-to-reference ratio computed by the ray-matching approach and the RTC approach for January 2017.

\begin{tabular}{cccccccc}
\hline & & $\begin{array}{c}\text { Band 1 } \\
(0.47 \mu \mathrm{m})\end{array}$ & $\begin{array}{c}\text { Band 2 } \\
(0.51 \mu \mathrm{m})\end{array}$ & $\begin{array}{c}\text { Band 3 } \\
(0.64 \mu \mathrm{m})\end{array}$ & $\begin{array}{c}\text { Band 4 } \\
(0.86 \mu \mathrm{m})\end{array}$ & $\begin{array}{c}\text { Band 5 } \\
(1.6 \mu \mathrm{m})\end{array}$ & $\begin{array}{c}\text { Band 6 } \\
(2.3 \mu \mathrm{m})\end{array}$ \\
\hline \multirow{2}{*}{ Ray-matching } & Mean & 0.979 & 0.970 & 1.030 & 1.008 & 1.067 & 0.954 \\
& Stdv & 0.007 & 0.008 & 0.008 & 0.007 & 0.009 & 0.008 \\
\hline \multirow{2}{*}{ RTC approach } & Mean & 0.991 & 0.984 & 1.020 & 1.029 & 1.045 & 0.967 \\
& Stdv & 0.015 & 0.017 & 0.019 & 0.017 & 0.011 & 0.008 \\
\hline
\end{tabular}


Fig. 8. Aqua/MODIS L1B C6 was also applied to this approach, and the difference brought about by $\mathrm{C} 5$ and C6 was less than $1 \%$ in the ratio for AHI Bands 1-6. The two-year trend shows that Bands 1-4 exhibit detector sensitivity degradation of around $0.5 \%$ per year, whereas the degradation trend is not significant in Bands 5 and 6. These trends show a close correlation with that validated using SCT observation as described in Section 2.3.

Monthly regression coefficients based on the RTC simulation approach are also shown in Table 7. These are derived from the observation and simulation from cloud-free ocean and liquid cloud top targets using the following linear regression equation:

$$
\begin{aligned}
& \text { Simulated_reflectivity } \\
& \quad=\text { Intercept }+ \text { Slope } \times \text { Observed_reflectivity. }
\end{aligned}
$$

It should be noted that this definition differs from that for the coefficients shown in Table 6. As described in Section 5.2.b, the cloud-free ocean target is not applied to Bands 1 and 2. The intercepts are set to zero for these bands, and the uncertainties on the intercepts for Bands 3-6 (Table 7) are in the same order as those described in Section 5.2.b. This implies that linear regression offsets for these bands could be negligible.

This section describes detector-averaged sensitivity changes, whose relative values among detectors over time can cause striping and banding. Related validation is outside the scope of this study but will be considered in future work.

\section{Monitoring}

AHI image quality is monitored in real time at JMA's MSC. INR errors are evaluated by landmark analysis (Tabata et al. 2016), and such errors are monitored to determine whether they exceed predetermined thresholds. Similarly, a monitoring system is used internally at the JMA mainly to check the calibration performance. The system compares Full-Disk observations with the previous one (from 10 minutes before) to identify sudden unexpected anomalies on a real-time basis. This GEO-GEO comparison approach supports the detection of anomalies in images, such as lunar interference (Fig. 9a) and stray light from solar interference (Figs. 9b, c) (Shao et al. 2016). Intercalibration involving the use of hyperspectral IR sounders and other collocation-based approaches as described in Sections 4 and 5 is effective for quanti-

Table 7. Monthly regression coefficients by RTC simulation and observation for AHI- 8 VNIR bands based on the cloudfree ocean and the liquid cloud top targets. Note that definition of the coefficients is different from the one used for Fig. 8

\begin{tabular}{|c|c|c|c|c|c|c|c|c|c|c|c|c|c|}
\hline & & \multicolumn{2}{|c|}{ B01 } & \multicolumn{2}{|c|}{ B02 } & \multicolumn{2}{|c|}{ B03 } & \multicolumn{2}{|c|}{ B04 } & \multicolumn{2}{|c|}{ B05 } & \multicolumn{2}{|c|}{ B06 } \\
\hline & & Intercept & Slope & tercept & Slope & atercept & Slope & tercept & Slope & Intercept & Slope & ntercept & Slope \\
\hline \multirow[t]{6}{*}{2015} & Jul & - & 00032 & - & 0.9994 & 0.0017 & 0.9682 & 0.0010 & 9609 & 0.0008 & 0.9493 & -0.0020 & 1.0633 \\
\hline & Aug & - & & - & 1.0028 & -0.0013 & 0.9732 & 0.0010 & 0.9654 & -0.0011 & 0.9478 & .0017 & 1.0477 \\
\hline & Sep & - & 0.9964 & - & 1.0034 & -0.0014 & 0.9714 & -0.0011 & 0.9620 & -0.0014 & 0.9507 & -0.0015 & 1.0488 \\
\hline & Oct & - & 0.9974 & - & 1.0051 & -0.0005 & 0.9715 & -0.0006 & 0.9639 & -0.0016 & 0.9 & -0.0015 & 1.0458 \\
\hline & Nov & - & 1.0041 & - & 1.0116 & -0.0005 & 0.9758 & -0.0011 & 0.9706 & -0.0021 & 0.9 & -0.0021 & 1.0508 \\
\hline & Dec & - & 09993 & - & 1.0057 & -0.0005 & 0.9726 & -0.0011 & 0.9654 & 0025 & 0.9 & 020 & 1.0426 \\
\hline \multirow[t]{12}{*}{2016} & 4 & - & & - & & ד ד & & & & & & & \\
\hline & Feb & - & 1.0047 & - & 1.01 & -0.0002 & 0.97 & -0.0003 & 0.9727 & -0.0019 & 0.9 & -0.0 & 1.0384 \\
\hline & Mar & - & 1.0028 & - & 1.0097 & -0.0009 & 0.9753 & -0.0013 & 0.9670 & -0.0025 & 0.9630 & -0.0022 & 1.0463 \\
\hline & Apr & - & & - & & & & -0.0012 & & & & & \\
\hline & May & - & 1 & - & 1.0185 & -0.0021 & 0.9866 & -0.0016 & 0.9763 & -0.0020 & 0.9 & -0 & 1.0591 \\
\hline & Jun & - & & - & 1.0011 & -0.0018 & 0.9712 & -0.0014 & 0.9643 & -0.0011 & & 17 & 1.0653 \\
\hline & Jul & - & & - & & & & -0.0010 & & -0.0011 & & -0.0020 & 1.0593 \\
\hline & Aug & - & & - & 1.0175 & -0.0020 & 0.9902 & -0.0016 & 0.9 & -0.0013 & 0.9 & -0 . & 1.0603 \\
\hline & Sep & - & 1.00 & - & & -0.0009 & & -0.0010 & & & & 16 & 1.0447 \\
\hline & Oct & - & & - & & -0.0012 & 0.9851 & -0.0012 & & -0.0019 & & -0.0013 & 1.0426 \\
\hline & Nov & - & 1.0175 & - & 1.0255 & -0.0001 & 0.9910 & -0.0004 & 0.9841 & -0.0020 & 0.9655 & -0.0019 & 1.0553 \\
\hline & Dec & - & 1.0135 & - & 1.0218 & -0.0006 & 0.9890 & -0.0010 & 0.9830 & -0.0023 & 0.9610 & -0.0019 & 1.0454 \\
\hline \multirow[t]{3}{*}{2017} & Jan & - & 10 & - & 1.022 & 0.0004 & 0.9866 & 0.0000 & 0.9803 & -0.0019 & & 18 & 1.0414 \\
\hline & & - & & - & & 0.0002 & 0.9910 & -0.0002 & 0.9831 & -0.0017 & 0.9581 & -0.0018 & 1.0367 \\
\hline & Mar & - & 1.0130 & - & 1.0215 & -0.0008 & 0.9905 & -0.0007 & 0.9785 & -0.0016 & 0.9594 & -0.0015 & 1.0477 \\
\hline
\end{tabular}
and Table 6. 

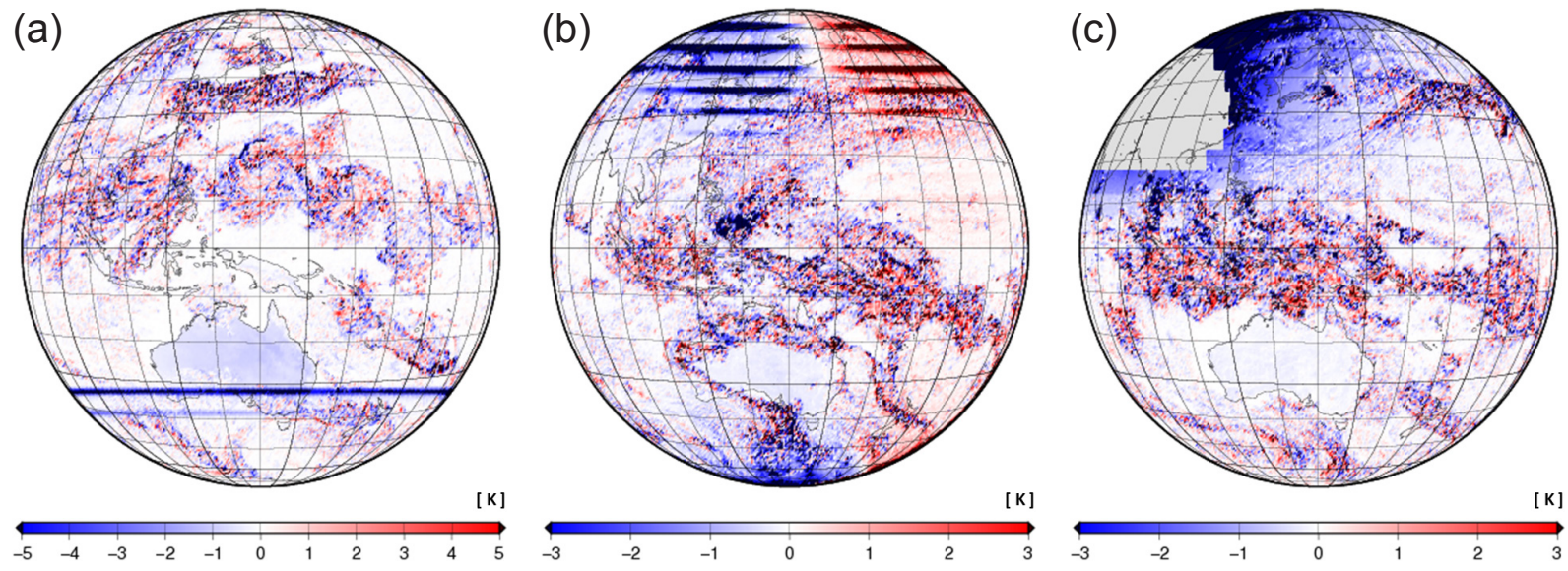

Fig. 9. a) Band $13 \mathrm{~Tb}$ difference image compared with an image on a previous timeline for 06:50-06:40 UTC, 6 July 2015. The blue line over southern Australia represents the effect of lunar interference. Radiation from the moon's surface was included among the deep-space counts for on-board calibration. This issue was fixed on 7 September 2015 with an update to the ground processing system.; b) Band $7 \mathrm{~Tb}$ difference image for 15:0014:50 UTC, 14 February 2017. A stripe of stray light is seen moving from west to east in the northern part of the full-disk imagery, and is stronger (weaker) in the red (blue) area.; c) Band $7 \mathrm{~Tb}$ difference for 14:20-14:10 UTC, 03 April 2017. An effect of stray light is observed in the blue part near the chipped region.

tative estimation of biases, although the collection of GEO and LEO satellite data essentially takes longer than preparations for GEO-GEO comparison because of the greater latency of LEO data. The monitoring system described here cannot be established without the advantages of real-time data acquisition in the GEO-GEO approach and its wide data coverage. The GEO-GEO approach also helps clarify diurnal calibration variations by complementing missing periods of GEO-LEO collocation time, and work on its development remains ongoing.

\section{Conclusion}

The AHI's spatial, spectral, and temporal resolutions are superior to those of the imagers on the predecessor MTSAT-series satellites. This paper reports on the radiometric calibration performance of all AHI8's VNIR and IR bands. The estimated Tb biases for IR bands are less than $0.3 \mathrm{~K}$ in standard scenes, and there is no significant diurnal variation. Okamoto (2017) and Zou et al. (2016) also assessed AHI-8's IR band data quality using NWP data and reported an apparent $\mathrm{Tb}$ bias. The cause of these biases is yet to be determined. The GSICS IR calibration approach revealed undesirable diurnal calibration variations in IR data during AHI-8's early commissioning phase and helped identify erroneous onboard calibration processing in the ground segment. VNIR band cali- bration was validated via ray-matching with S-NPP/ VIIRS and RTC with Aqua/MODIS as a reference. The results indicated that AHI- 8 Bands 1-4 have no significant biases with reference to VIIRS and MODIS but exhibit trends of sensor sensitivity degradation at approximately $0.5 \%$ per year, whereas Bands 5 and 6 exhibit positive and negative biases of about $5 \%$ with no clear degradation. These validation outcomes also show close correspondence with SCT observation analysis results. Both this study and the operational AHI-8 level 1 data processing system have involved the use of static VNIR calibration slopes derived from SCT observations made between March and May 2015. The latest VNIR calibration information derived from SCT observations was also added to the HSD header, and this information is updated periodically (Japan Meteorological Agency 2017b).

The AHI's enhanced observation capability (based on multiple bands, finer special resolution, and improved temporal resolution) is expected to provide a greater wealth of information for use in new applications (e.g., for information on ocean color, flood monitoring, and vegetation index) not derived from heritage GEO imager data. To support the full utilization of AHI-8 data in a wide variety of applications (e.g., data assimilation in NWP models, retrieval for geophysical products, nowcasting, and climate monitoring), more accurate and stable radiometric calibration 
and validation are needed. Small diurnal variations in IR bands and discrepancies in validation results for VNIR bands can be re-examined with checking of the onboard ICT calibration system and investigation to determine the possible root causes of the discrepancies described in Section 5.3, respectively. Revisiting analysis of SCT observation data to reduce seasonal variations and developing new calibration/validation methods such as DCC intercalibration and lunar calibration will contribute significantly to the monitoring of long-term calibration stability. The analyses will be reported in the future. Yu and $\mathrm{Wu}$ (2016) reported that AHI observation could involve a greater uncertainty in lower-radiance regions based on their application of the ray-matching approach using S-NPP/VIIRS. As JMA's preliminary analysis also shows similar results, further validation work focusing on lower-radiance regions in VNIR bands is required. Blending these calibration methods is also expected to provide more reliable validation results covering the whole dynamic ranges of AHI VNIR bands.

\section{Acknowledgments}

The authors appreciate the input of all who contributed to the validation of the AHI commissioning dataset. Particular thanks go to Dr. Hiroshi Murakami, Dr. Hideaki Takenaka and Prof. Teruyuki Nakajima of JAXA/EORC, to Dr. Xiangqian Wu, Dr. Fangfang Yu and the ABI calibration team at NOAA/NESDIS and Dr. Xiaoxiong Xiong at NASA/GSFC. The authors are grateful to OpenCLASTR project for using CAPCOM, REAP and RSTAR packages in this research. The authors also would like to thank the members of the prime contractor of Himawari-8 and -9, Mitsubishi Electric Corporation, for the development and the maintenance of AHI's ground processing system as well as the members of the sensor vender, Harris Corporation, for the excellent development of AHI. This research was partially supported by JST CREST Grant Number JPMJCR1312 (Research Director: Dr. Takemasa Miyoshi). The authors would like to thank the members of the project for valuable comments.

\section{References}

Bessho, K., K. Date, M. Hayashi, A. Ikeda, T. Imai, H. Inoue, Y. Kumagai, T. Miyakawa, H. Murata, T. Ohno, A. Okuyama, R. Oyama, Y. Sasaki, Y. Shimazu, K. Shimoji, Y. Sumida, M. Suzuki, H. Taniguchi, H. Tsuchiyama, D. Uesawa, H. Yokota, and R. Yoshida, 2016: An Introduction to Himawari-8/9 - Japan's newgeneration geostationary meteorological satellites. $J$. Meteor. Soc. Japan, 94, 151-183.
Bruegge, C. J., A. E. Stiegman, R. A. Rainen, and A. W. Springeteen, 1993: Use of Spectralon as a diffuse reflectance standard for in-flight calibration of earthorbiting sensors. Opt. Eng., 32, 805-814.

Commitee on Earth Observation Satellites, 2016: Non-meteorological applications for next generation geostationary satellites study. Proceeding of 30th CEOS Plenary, Brisbane, Australia. [Available at http://ceos. org/document_management/Meetings/Plenary/30/ Documents/6.1_Schroeder_NMA_Report_2016-0905 _v.2.00.pdf.]

Da, C., 2015: Preliminary assessment of the Advanced Himawari Imager (AHI) measurement onboard Himawari-8 geostationary satellite. Remote Sens. Lett., 6 , 637-646.

Datla, R., X. Shao, C. Cao, and X. Wu, 2016: Comparison of the calibration algorithms and SI traceability of MODIS, VIIRS, GOES, and GOES-R ABI sensors. Remote Sens., 8, doi:10.3390/rs8020126.

Doelling, D. R., R. Bhatt, D. Morstad, and B. Scarino, 2011: Algorithm Theoretical Basis Document (ATBD) for ray-matching technique of calibrating GEO sensors with Aqua-MODIS for GSICS. [Available at http:// gsics.atmos.umd.edu/pub/Development/AtbdCentral/ GSICS_ATBD_RayMatch_NASA_2011_09.pdf.]

Doelling, D. R., D. Morstad, B. R. Scarino, R. Bhatt, and A. Gopalan, 2013: The characterization of deep convective clouds as an invariant calibration target and as a visible calibration technique. IEEE Trans. Geosci. Remote Sens., 51, 1147-1159.

Erives, H., X. Xiong, J. Sun, J. A. Esposito, S. Xiong, and W. Barnes, 2004: Terra MODIS RSB on-orbit calibration and performance: Four years of data. Proceedings of SPIE Vol. 5570, Sensors, Systems, and Next-Generation Satellites VIII. Meynart, R., S. P. Neeck, and H. Shimoda (eds.), Remote Sens., Canary Islands, Spain.

Goldberg, M., G. Ohring, J. Butler, C. Cao, R. Datla, D. Doelling, V. Gärtner, T. Hewison, B. Iacovazzi, D. Kim, T. Kurino, J. Lafeuille, P. Minnis, D. Renaut, J. Schmetz, D. Tobin, L. Wang, F. Weng, X. Wu, F. Yu, P. Zhang, and T. Zhu, 2011: The Global Space-based Inter-Calibration System (GSICS). Bull. Amer. Meteor. Soc., 92, 468-475.

Griffith, P. C., 2015: Advanced Himawari Imager (AHI) design and operational flexibility. The sixth Asial Oceania Meteorological Satellite Users' Conference (AOMSUC-6), November 2015, Tokyo, Japan.

Griffith, P. C., 2016a: Significant increase in geostationary imaging temporal resolution for GEO-KOMPSAT2A AMI. The seventh Asia/Oceania Meteorological Satellite Users' Conference (AOMSUC-7), October 2016, Songdo, Korea.

Griffith, P. C., 2016b: Himawari-8 coherent noise reduction. The seventh Asia/Oceania Meteorological Satellite Users' Conference (AOMSUC-7), October 2016, Songdo, Korea. 
Gunshor, M. M., T. J. Schmit, W. P. Menzel, and D. C. Tobin, 2006: Intercalibration of the newest geostationary imagers via high spectral resolution AIRS data. 14th Conference on Satellite Meteorology and Oceanography, 29 January-2 February 2006, Atlanta, GA.

Hewison, T. J., X. Wu, F. Yu, Y. Tahara, X. Hu, D. Kim, and M. Koenig, 2013: GSICS inter-calibration of infrared channels of geostationary imagers using Metop/IASI. IEEE Trans. Geosci. Remote Sens., 51, 1160-1170.

Higurashi, A., 1998: A study of aerosol properties on global scale using satellite remote sensning. $\mathrm{Ph}$. D. thesis, University of Tokyo, $95 \mathrm{pp}$.

Higurashi, A., and T. Nakajima, 1999: Development of a two-channel aerosol retrieval algorithm on global scale using NOAA/AVHRR. J. Atmos. Sci., 56, 924941.

Higurashi, A., and T. Nakajima, 2002: Detection of aerosol types over the East China sea near Japan from fourchannel satellite data. Geophys. Res. Lett., 29, 1836, doi:10.1029/2002GL015357.

Higurashi, A., T. Nakajima, B. N. Holben, A. Smirnov, R. Frouin, and B. Chatenet, 2000: A study of global aerosol optical climatology with two-channel AVHRR remote sensing. J. Climate, 13, 2011-2027.

Ishimoto, H., K. Masuda, Y. Mano, N. Orikasa, and A. Uchiyama, 2013: Optical modeling of irregularly shaped ice particles in convective cirrus. AIP Conf. Proc., 1531, 184, doi:10.1063/1.4804737.

Japan Meteorological Agency, 2013: JMA's GSICS and SCOPE-CM Activities. CGMS-41-JMA-WP-04, the 41th Meeting of the Coordination Group for Meteorological Satellites, 8-12 July 2013, Tsukuba, Japan.

Japan Meteorological Agency, 2017a: Himawari Standard Data User's Guide (Version 1.3). [Available at https:// www.data.jma.go.jp/mscweb/en/himawari89/space segment/hsd_sample/HS_D_users_guide_en_v13.pdf.]

Japan Meteorological Agency, 2017b: Improvement of Himawari-8 observation data quality. [Available at https://www.data.jma.go.jp/mscweb/en/operation8/ eventlog/Improvement_of_Himawari-8_data_quality. pdf.]

Kawamoto, K., T. Nakajima, and T. Y. Nakajima, 2001: A global determination of cloud microphysics with AVHRR remote sensing. J. Climate, 14, 2054-2068.

Kobayashi, S., Y. Ota, Y. Harada, A. Ebita, M. Moriya, H. Onoda, K. Onogi, H. Kamahori, C. Kobayashi, H. Endo, K. Miyaoka, and K. Takahashi, 2015: The JRA-55 Reanalysis: General specifications and basic characteristics. J. Meteor. Soc. Japan, 93, 5-48.

Kosaka, Y., A. Okuyama, H. Takenaka, and S. Fukuda, 2012: Development and improvement of a vicarious calibration technique for the visible channel of geostationary meteorological satellite. Meteorol. Satell. Cent. Tech. Note, 57, 39-55 (in Japanese).

Kurucz, R. L., 1995: The solar irradiance by computation.
Proceedings of the 17th Annual Conference on Atmospheric Transmission Models, 8-9 June 1994. Anderson, G. P., R. H. Picard, and J. H. Chetwynd (eds.), PL/-TR-95-2060(I), Special Reports, 274, Phillips Laboratory/Directorate of Geophysics, 333-334.

Letu, H., H. Ishimoto, J. Riedi, T. Y. Nakajima, L. C.-Labonnote, A. J. Baran, T. M. Nagao, and M. Sekiguchi, 2016: Investigation of ice particle habits to be used for ice cloud remote sensing for the GCOM-C satellite mission. Atmos. Chem. Phys., 16, 12287-12303.

Liang, X., A. Ignatov, M. Kramar, and F. Yu, 2016: Preliminary inter-comparison between AHI, VIIRS and MODIS Clear-sky Ocean Radiances for accurate SST retrievals. Remote Sens., 8, 203, doi:10.3390/ rs8030203.

Murakami, H., 2016: JAXA Himawari-8 ocean color and aerosol. Annual Meeting of $G R W G+G D W G$, February 2016, Tsukuba, Japan.

Murata, H., M. Takahashi, and Y. Kosaka, 2015: VIS and IR bands of Himawari-8/AHI compatible with those of MTSAT-2/Imager. Meteorol. Satell. Cent. Tech. Note, 60, 1-18.

Nakajima, T., and M. Tanaka, 1986: Matrix formulation for the transfer of solar radiation in a plane-parallel scattering atmosphere. J. Quant. Spectrosc. Radiat. Transfer, 35, 13-21.

Nakajima, T., and M. Tanaka, 1988: Algorithms for radiative intensity calculations in moderately thick atmospheres using a truncation approximation. J. Quant. Spectrosc. Radiat. Transfer, 40, 51-69.

Nakajima, T., and A. Higurashi, 1998: A use of two-channel radiances for an aerosol characterization from space. Geophys. Res. Lett., 25, 3815-3818.

Nakajima, T. Y., and T. Nakajima, 1995: Wide-area determination of cloud microphysical properties from NOAA AVHRR measurements for FIRE and ASTEX regions. J. Atmos. Sci., 52, 4043-4059.

Nakajima, T. Y., K. Suzuki, and G. L. Stephens, 2010a: Droplet growth in warm water clouds observed by the A-Train. Part I: Sensitivity analysis of the MODISderived cloud droplet sizes. J. Atmos. Sci., 67, 18841896.

Nakajima, T. Y., K. Suzuki, and G. L. Stephens, 2010b: Droplet growth in warm water clouds observed by the A-Train. Part II: A multi-sensor view. J. Atmos. Sci., 67, 1897-1907.

Okamoto, K., 2017: Evaluation of IR radiance simulation for all-sky assimilation of Himawari-8/AHI in a mesoscale NWP system. Quart. J. Roy. Meteor. Soc., 143, 1517-1527.

Okuyama, A., A. Andou, K. Date, K. Hosaka, N. Mori, H. Murata, T. Tabata, M. Takahashi, R. Yoshino, and K. Bessho, 2015: Preliminary validation of Himawari-8/ AHI navigation and calibration. Proc. SPIE 9607, Earth Observing Systems XX, 96072E, doi:10.1117/ 12.2188978 . 
Scarino, B. R., D. R. Doelling, P. Minnis, A. Gopalan, T. Chee, R. Bhatt, C. Lukashin, and C. Haney, 2016: A web-based tool for calculating spectral band difference adjustment factors derived from SCIAMACHY hyperspectral data. IEEE Trans. Geosci. Remote Sens., 54, 2529-2542.

Schmit, T. J., M. M. Gunshor, W. P. Menzel, J. J. Gurka, J. $\mathrm{Li}$, and S. Bachmeier, 2005: Introducing the next-generation Advanced Baseline Imager on GOES-R. Bull. Amer. Meteor. Soc., 86, 1079-1096.

Schmit, T. J., J. Li, J. J. Gurka, M. D. Goldberg, K. J. Schrab, J. Li, and W. F. Feltz, 2008: The GOES-R Advanced Baseline Imager and the continuation of current sounder products. J. Appl. Meteor. Climatol., 47, 2696-2711.

Schmit, T. J., P. Griffith, M. M. Gunshor, J. M. Daniels, S. J. Goodman, and W. J. Lebair, 2017: A closer look at the ABI on the GOES-R series. Bull. Amer. Meteor. Soc., 98, 681-698.

Shao, X., X. Wu, and F. Yu, 2016: Characterization of Himawari-8 AHI 3.9-um channel stray light. Proc. SPIE 9972, Earth Observing Systems XXI, 99720R, doi:10.1117/12.2237052.

Stamnes, K., S.-C. Tsay, W. Wiscombe, and K. Jayaweera, 1988: Numerically stable algorithm for discreteordinate-method radiative transfer in multiple scattering and emitting layered media. Appl. Opt., 27, 25022509.

Sun, J., X. Xiong, A. Angal, H. Chen, A. Wu, and X. Geng, 2014: Time-dependent response versus scan angle for MODIS reflective solar bands. IEEE Trans. Geosci. Remote Sens., 52, 3159-3174.

Tabata, T., A. Andou, K. Bessho, K. Date, R. Dojo, K. Hosaka, N. Mori, H. Murata, R. Nakayama, A. Okuyama, and M. Takahashi, 2016: Himawari-8/AHI latest performance of navigation and calibration. Proc. SPIE 9881, Earth Observing Missions and Sensors: Development, Implementation, and Characterization IV, 98812J, doi:10.1117/12.2240200.
Tahara, Y., and K. Kato, 2009: New spectral compensation method for intercalibration using high spectral resolution sounder. Meteorol. Satell. Cent. Tech. Note, 52, $1-37$.

Takahashi, M., 2016: Inter-calibration of Himawari-8/AHI using CrIS as a reference. GSICS User's Workshop 2016, 11 August 2016, College Park, Maryland, USA.

Takahashi, M., and A. Okuyama, 2017: Introduction to the Global Space-based Inter-Calibration System (GSICS) and Calibration/Validation of the Himawari-8/AHI visible and infrared bands. Meteorol. Satell. Cent. Tech. Note, 62, 1-18 (in Japanese).

Tobin, D. C., H. E. Revercomb, C. C. Moeller, and T. S. Pagano, 2009: Use of Atmospheric Infrared Sounder high-spectral resolution spectra to assess the calibration of Moderate resolution Imaging Spectroradiometer on EOS Aqua. J. Geophys. Res., 111, D09S05, doi:10.1029/2005JD006095.

Xiong, X., J. Butler, K. Chiang, B. Efremova, J. Fulbright, N. Lei, J. McIntire, H. Oudrari, Z. Wang, and A. Wu, 2016: Assessment of S-NPP VIIRS on-orbit radiometric calibration and performance. Remote Sens., 8, 84, doi:10.3390/rs8020084.

Yokota, H., and M. Sasaki, 2013: Introduction to Himawari-8 and 9. Meteorol. Satell. Cent. Tech. Note, 58, 121-138 (in Japanese).

Yu, F., X. Wu, M. K. R. V. Raja, Y. Li, L. Wang, and M. Goldberg, 2013: Diurnal and scan angle variations in the calibration of GOES imager infrared channels. IEEE Trans. Geosci. Remote Sens., 51, 671-683.

$\mathrm{Yu}, \mathrm{F}$, and $\mathrm{X}$. Wu, 2016: Radiometric inter-calibration between Himawari-8 AHI and S-NPP VIIRS for the solar reflective bands. Remote Sens., 8, 165, doi: $10.3390 /$ rs 8030165 .

Zou, X., X. Zhuge, and F. Weng, 2016: Characterization of bias of Advanced Himawari Imager infrared observations from NWP background simulations using CRTM and RTTOV. J. Atmos. Oceanic Technol., 33, 2553-2567. 